\title{
القيم والمرجعية القيمية في التعليم الجامعي
}

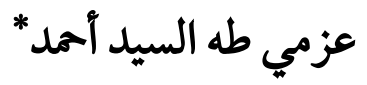

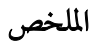

تروم هذه الدراسة العلمية توضيح مفهوم "القيمة" الذي اعتمده الباحث فيها، وبيان أهمية القيم في الحياة الإنسانية،

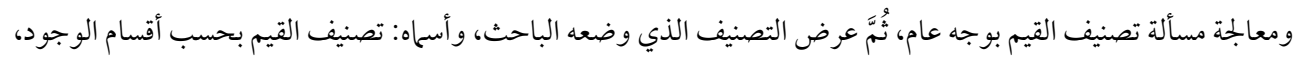

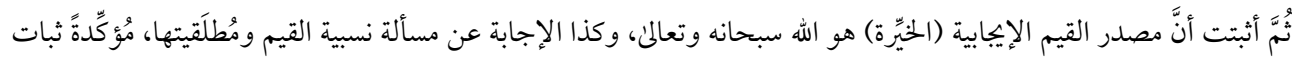

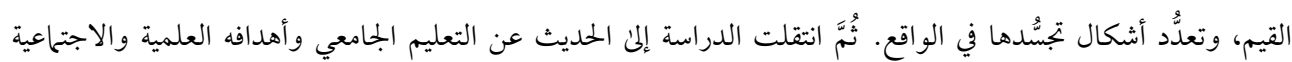

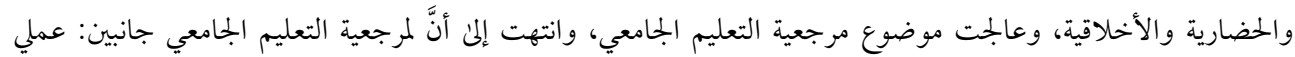

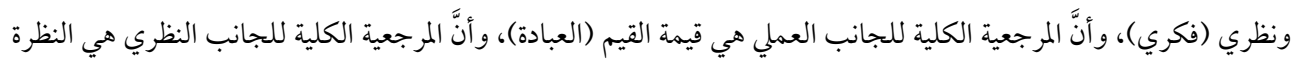

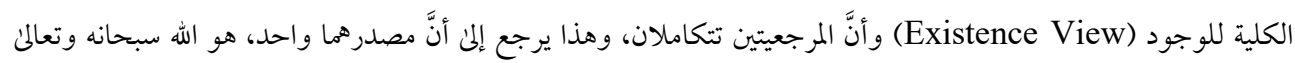

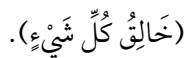
الكلمات المفتاحية: القيم، القيم الإيجابية، قيمة القيم، الرؤية الكلية للوجود، المرجعية القيمية.

* دكتوراه في الفلسفة الإسلامية، أستاذ جامعي في عدد من الجامعات الأردنية. البريد الإلكتروني: abutaha.azmi@gmail.com

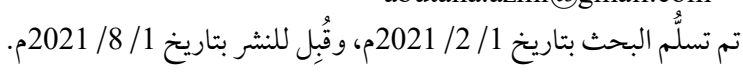

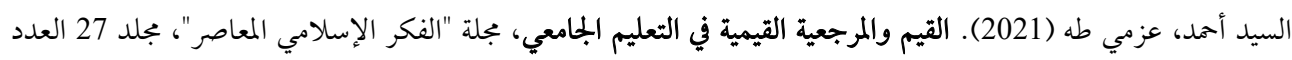

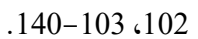

DOI: 10.35632/citj.v27i102.5981

كافة الحقوق محفوظة للمعهد العالمي للفكر الإسلامي 2021 
مقدمة: - n

يشهد وقتنا الحاضر اهتماماً بالبحث في القيم وحقيقتها وأهميتها في حياة الأفراد والمجتمعات،

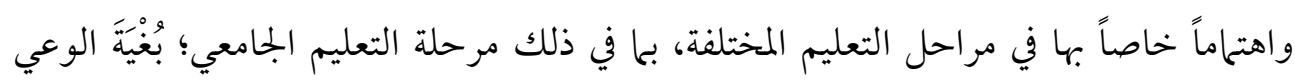
الأوفن بحقيقة القيم، ودورها الـمُهِم في الحياة الإنسانية؛ الأمر الذي يؤدي في نظر العديد من الباحثين إلن انتظام هذه الحياة، والارتقاء بها إلن أعلن الدرجات السمُمكِنة من الاستقرار، وتحقيق الخير والسعادة علن المستوىن الفردي والمستوى الجماعي. ستُعالِج هذه الدراسة جانباً من جوانب البحث في موضوع القيم؛ أي المرجعية التي تُحَّد في ضوئها القيم، وبيان حقيقة هذه المرجعية علن المستوكن العملي والمستوكن النظري (الفكري). ومن ثَمََّ، ستبدأ بتوضيح مفهوم "القيم"، وبيان أهميتها في حياة الإنسان، وتعداد أنواعها (تصنيفاتها)،

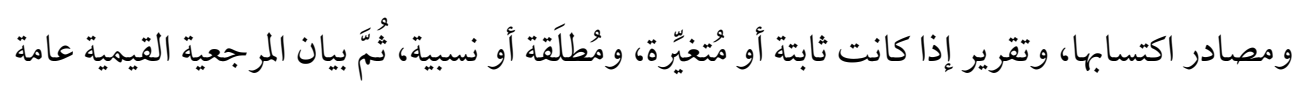
في جانبها النظري وجانبها العملي، ثُمَّم عرض ما توصَّلت إليه من نتائج.

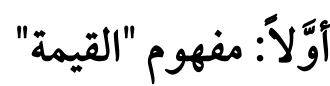

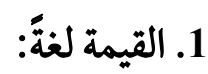

كلمة "قيمة" في اللغة العربية تدل غالباً علن تقديرٍ للأمور المادية، مثل: تقييم سلعة ما بتحديد

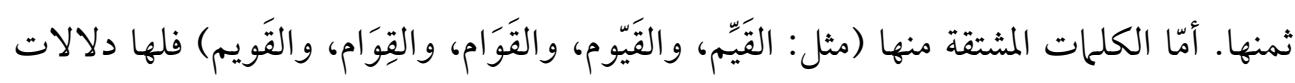
إيجابية غير مادية.

ومّّا ورد في "المعجم الوسيط": "قيمة الشي قدره، وقيمة المتاع ثمنه ...، ويقال: ما لفلان قيمة: ما له ثبات ودوام علن الأمر." و"القَيَوم: القائم الحافظ لكل شيء، والقَيّوم: اسم من أسماء الله الحسنح، و القَيِّم: السيّّد، وسائس الأمر، وقَيَّم القوم: الذي يقوم بشأنهم، ويسوس أمرهم، وأمر قيّمّ: مستقيم، ودين القيّمة (المستقيم، والـمُعتدِل) " (بجمع اللغة العربية في القاهرة، 2011، مادة قام). 


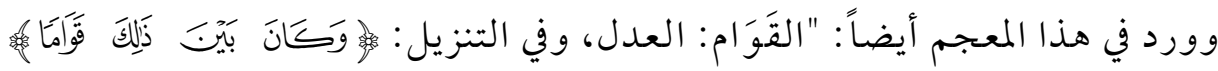
[ الفرقان:67]. و القِوَام: قِوَوَام كل شيء: عماده ونظامه" (بجمع اللغة العربية في القاهرة،

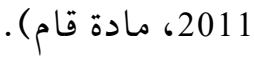

وهذه المعاني اللغوية تُعبِّ بشكل تقريبي عن المعاني الاصطلاحية الحديثة التي يتضمَّنها مفهوم "القيمة"، وتوجد ألفاظ أُخرىن عبَّرت عن بعض هذه المعاني الاصطلاحية، مثل: الحلال والحرام، تعرئ وأفعال التفضيل، والألفاظ الدالَّة على ما يتمنّاه المرء وما يسعنى لتحقيقه. وهذا يعني أنَّ القيم كانت تُّارَس من خلال السلوك الإنساني الفردي والجماعي، وإنْ لم توجد مباحث مُتخصِّصة في دراستها كالذي نشهده في العصر الحاضر.

\section{2. - 2 القيمة اصطلاحاً:}

تعلَّدت التعريفات الاصطلاحية لـ "القيمة"، بحسب المجال الذي تتعلَّق به. فمثلاً، عرَّف علماء النفس مفهوم "القيمة" علن نحوِ يختلف عنه عند علملء الاجتماع، وغيرها في المجالات التربوية، السياسية، الأخلاقية... وهكذا، بيد أنَّهُ يوجد جامع مُشتركَك بينها جميعاً، يُشَّلّ -في نظرنا- مفهوم

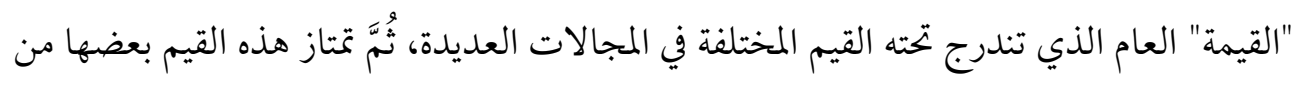
بعض بها يضاف إليها من سلات وخصائص ينفرد بها كل بجال من المجالات.

وقد وضعنا تعريفاً للقيمة، حاولنا فيه جمع العناصر الأساسية التي تنطوي عليها القيم. وهذا التعريف يتقاطع جزئياً مع العديد من التعريفات الـمُتداوَلة عند هذا العنصر أو ذاك، ولسنا هنا في مقام سرٍٍ للتعريفات المختلفة للقيمة عند السمُحدَثين من الغربيين، أو أهل المشرق عامة، وحسبنا إير اد تعريفنا الآتي الذي سنعتمده في المسائل التي تبحثها هذه الدراسة، وهو : "القيمة هي فكرة، أو مبدأ، أو صفة تكون محلَّ تقديرنا، وتُمثّل معياراً نحكم به علن الأشياء أو

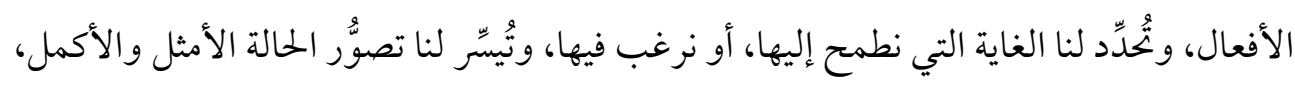
أو التي ينبخي أنْ تكون، وهي تقوم بدور الحافز لنا علن تحقيق الغاية المرغوبة، كما تقوم بتوجيه 
سلوكنا باتِّاه تحقيق الغاية التي تُمثّلها، وتنظيم أمور حياتنا على مستوىن الفرد، وعلى مستوىن

$$
\text { المجتمع " (السيد أحمد، 2015، ص201). }
$$

إنَّ النظرة المباشرة في هذا التعريف تُبِّن عناصره التي هي أساسية وجوهرية (الذاتيات)؛

فالقيمة هي فكرة، أو مبدأ، أو صفة. وهذا يعني أنَّها أمر مستقل عن ذواتنا؛ سواء أكان واضعها الإنسان، أم خالق الإنسان. ثُّمّ هي محلّ تقديرنا الإيجابي؛ لأهمية الدور الذي تؤديه في حياتنا، وتشير إليه العناصر الأساسية الأخرىن الـمُكوِّنة لمفهومها؛ فهي معيار نحكم به على الأفعال، أو أو الأشياء، أو الأشخاص. ومن دون هذه القيمة، وهذا المعيار، لا يُمكِنِا إصدار أحكام مُنضبِطة على أفعال الإنسان، أو على الأشياء، ومن دونها تكون أحكامنا كلها جز افية؛ فالذي يصف إنساناً، أو قاضياً، أو مسؤولاً بالعدل، لا يُقبَل منه هذا الحكم إلّا إذا كان على معرفة ووعي بمفهوم "العدالة". وحتّى في حال تقييم الأشياء المادية عن طريق أثحانها، فإنَّ التقييم الصحيح يقوم به فقط مَنْ يعرف حقيقة هذه الأشياء، أمّا مَنْ يجهلها فسيكون تقييمه جزافاً؛ زيادةً، أو تطفيفاً. وللقيم صلة جوهرية بالغايات التي نطمح إلى تحقيقها، أو الاقتراب من ذلك ما أمكن.1 فمثلاً، قيمة الحرية تُمثِّل للأفراد والمجتمعات والشعوب غاية يُجاهِدون لتحقيقها، وكثيراً ما يُضحّي أُناس بحياتهم من أجل الحرية. ومن ثََّّ، فتحقيق الحرية في المجتمع على مستوىن الأفراد و مستوىن الجماعة -نقصد هنا الحرية المسؤولة، لا الحرية الـمُطلَقة- يُجِِّد الحالة المثلى الكاملة التي يسعى الأفر اد والمجتمعات إلى تحقيقها. ولا شكَّ في أنَّ الوعي بقيمة الحرية يساعدنا على تعرّف الحالة المثلى، أو التي ينبغي أنْ يكون عليها حال الأفراد والجماعات. وكذلك فإنَّ الوعي بالقيم عامة (مثل : قيمة الحرية، وقيمة العدالة) يُوجِّه سلو كنا نحو تجسيد هذه القيم في واقعنا، ويُعَلَّ دافعاً وحافزاً إلىا تحقيقها في الحياة؛ شرط أنْ نعي أهميتها ودورها في تنظيم أمور حياتنا كلها. 1 الكلام هنا عن القيم التي تُّقِق الخير والعمر ان والكمال للإنسان، وبعض الباحثين يُطلِق عليها اسم القيم الإيجابية، في مقابل

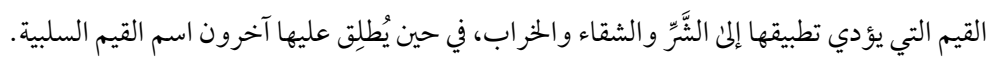


إنَّ الصفات المذكورة آنفاً عو امل رئيسية تُسهِم بفاعلية في تنظيم شؤون حياتنا، ولا سيّما

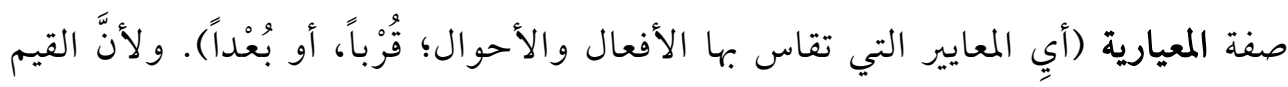
تساعدنا علن رسم صورةِ ما ينبغي أنْ تكون عليه أحو النا الفردية والجحاعية؛ فإنَّ تجسيد القيم

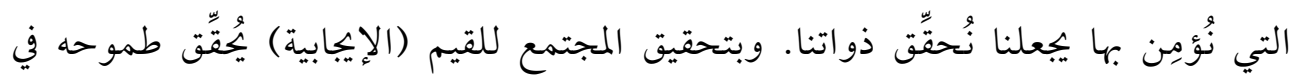
النهوض -إذا كان بصدد النهوض - ويحقق طموحه في المحافظة علن نهضته وتنميتها إذا كان متقدماً في مجال النهضة والحضارة. ومن ثَمَّ، فإنَّ الوعي بالقيم، وتجسيدها واقعاً، يُعَدُّ أحد الأركان الأساسية لقيام المجتمعات، ونهوضها، واستقرارها، والمحافظة على نهضتها و حضارتها.

\section{ثانياً: أهمية القيم في الحياة الإنسانية}

يَتبيَّن مثّا سبق أهمية القيم في الحياة الإنسانية علن مستون الفرد ومستون الجماعة، ويُجمِع الباحثون والمسؤولون في المجتمعات -علن اختلاف مواقعهم - علن ذلك.

يمكن أن نرى أهمية القيم (الإيجابية) في حياة الأفراد والمجتمعات إذا غابت هذه القيم من الحياة الإنسانية، فحياة الأفراد ستسير علن غير هدئ، فتكون مضطربة، ومشوَّة؛؛ فلا يستقيم لها حال، ولا ينتظم فيها مسار، وتغلب عليها الأهواء والشهوات، عندئذٍ ستتعارض أهواء الأفراد

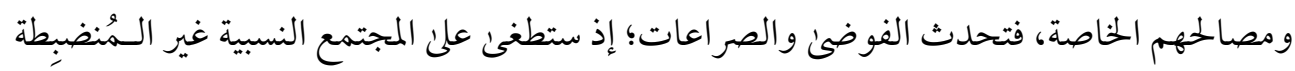

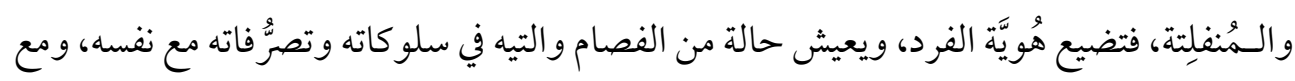
الآخرين.

أمّا إذا كان الفرد مُلتِِماً في سلوكه بقيم إيجابية، فإنَّنه سيكون مُنَّسقِاً مع ذاته، ومع المجتمع المحيط به؛ فيسَهل عليه التعامل مع الجمميع، بل ويمكن التنبؤ بما سيكون عليه سلوكه في المواقف

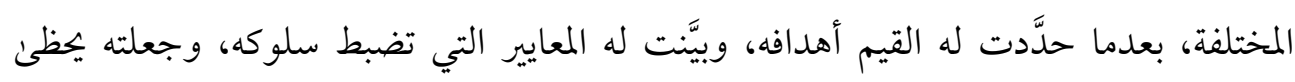
باحتر ام العقلاء. 
والإييان بالقيم الإيجابية، وتجسيدها في سلوك الفرد، يجعل لحياته معنًّ ومغزئً، بل إنه لا لا مبالغة في القول إنَّ معنى الحياة وقيمتها يستخلص من القيم التي يؤمن بها الفرد، فالقيم الإيجابية

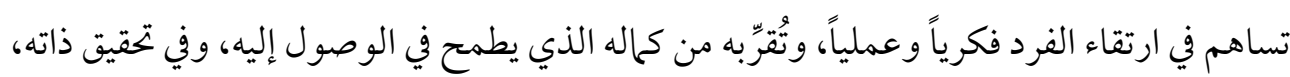
بما يُعَّقَه من إنجازات في ضوء هذه القيم. و القيم من حيث هي معايير للسلوك، وضوابط له، تُعِين الفرد علن ضبط جانب مُهِم من

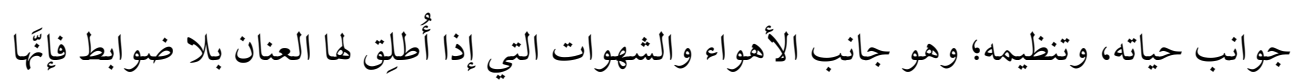
تؤذي صاحبها جسدياً ونفسياً. وقد حذَّر القرآن الكريم من الخطر العظيم الناجم عن اتِّباع الإنسان

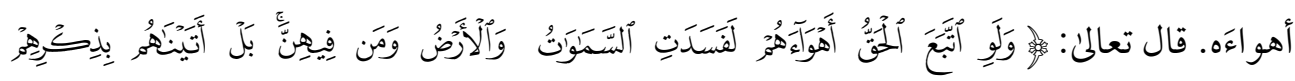

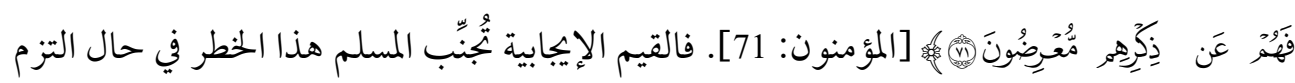
بها؛ ذلك أنهّا تمارس ضغرِاً اجتهاعياً ونفسياً عليه إذا حاول تجاوزها.

وبالمثل، فإنَّ للقيم أهمية كبرىن علن مستوى الجماعة، والمجتمع، والأمَّة، والدولة؛ ذلك أنَّا

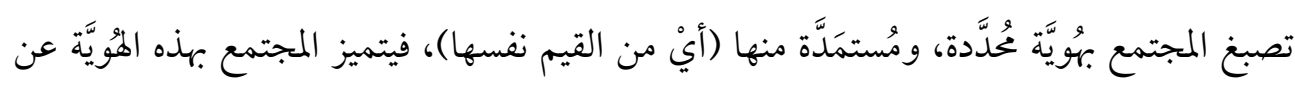
غيره من المجتمعات، وينفرد عنها بشخصيته وسماته وطبيعته؛ ما يؤُثِّ إيجاباً في استقر اره وتماسكه

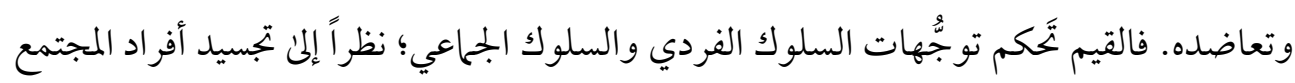

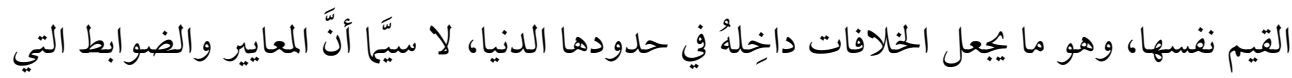

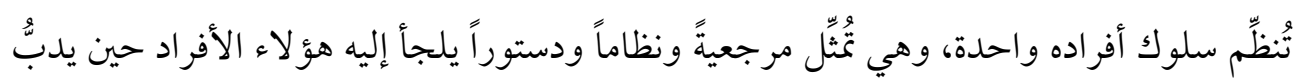
الخلاف بينهم.

وإذا كانت القيم تُمثّل -في جانب منها- الحالة المثلن التي يتطلَّع المجتمع إلن بلوغها، وتُمثّل -في

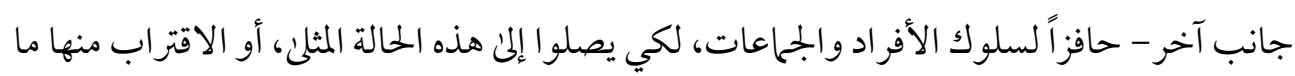
أمكن، فإنَّ القيم تؤدي دوراً فاعلاً في أنشطة المجتمع ومختلف مناحي حياته الاجتحاعية، والإنسانية،

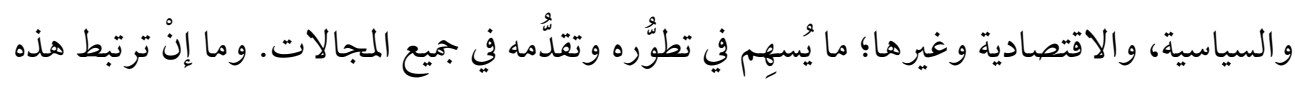
القيم بالعلم السمُوجَّه بها، حتّى يُحقِّق أفر اد المجتمع العديد من الإنجاز ات المادية وغير المادية، ويبدأ 
مسيرة النهوض الحضاري. أمّا إذا تراكمت هذه الإنجازات (المادية، وغير المادية)، فإنَّ المجتمع يصنع لنفسه حضارة2 (السيد أحمد، 2008، ص73-78) مُتميّزة بتلك القيم.

وفي سياق متصل، تؤدي القيم دوراً مُهِهاً في الحياة الاجتماعية استناداً إلى الثقافة السائدة في المجتمع؛ إذهي المرجعية المعيارية لهذه الثقافة، والثقافة هنا معرفة عملية ها جانب معياري يُبيِّن كيف يُمكِن التعامل مع جوانب الوجود كلها (السيد أحم، 2008، ص20 - 42)؛3 فهي ليست مُجرَّد أفكار، أو فلسفات وعلوم نظرية، وإنْ كان بين هذه الجو انب والثقافة صلات وعلاقات مُهِمَّة؛ ذلك أنَّ العمل في الاتجاه الصحيح يتطلَّب الركون إلن أفكار أو آراء نظرية صائبة.

وفي هذا الجانب، تختلف الثقافات بعضها عن بعض من حيث المرجعية القيمية، وقد يَتَّفِق بعضها مع بعض في ما يخصُّ كيفية التعامل مع جزء مُحَّد من الوجود، لكنَّ المرجعية الثقافية لكلٍ منها هي التي تُبيّن أوجه تمايزها من غيرها، ونضرب لذبك مثاك مثلاً أصحاب الثقافة الخاصة بالتعامل مع الخشب في مهنة النجارة؛ فهم ينحدرون من ثقافات مختلفة، ويهارسون غالباً الكيفية نفسها في إنيا قصِّ الأخشاب، وصنع أنواع الأثاث منها، لكنَّهم يختلفون في المرجعية القيمية لكلٍٍ منهم؛ فالنجّار صاحب المرجعية القيمية السمُستمَلَّة من الإسلام يختلف في عمله وتعامله -في نهاية المطاف- عن النجّار ذي المرجعية القيمية الـمُستمَدَّة من عقيدة علمانية. ومن ثَمَّ، فاختلاف المرجعية القيمية لكلِّ

$$
\text { منها ينعكس علن كيفية التعامل مع الأشياء. }
$$

لقد أشرنا آنفاً إلن أنَّ القيم هي العامل الحاسم في تشكيل هويَّة المجتمع، ولهذا سعت أمريكا وحلفاؤها إلن فرض نظام العولمة على الدول والمجتمعات الأخرىن، وكان سبيلها إنى ذلك هو محاولة فرض القيم العلمانية الأمريكية عليها. بيد أنَّ هذه المحاو لات باءت بالفشل في المجتمعات التي أظهرت تشبُثاً بقيمها، ولم تُفِلح مساعي القوى العظمى في فرض قيمها على هذه المجتمعات، ولو بالقوَّة.

2² انظر تعريفنا للحضارة في كتابنا علم الثقافة الإسلامية: مدخل. 3 انظر تعريفنا للثقافة والثقافة الإسلامية في كتابنا علم الثقافة الإسلامية: مدخل. 


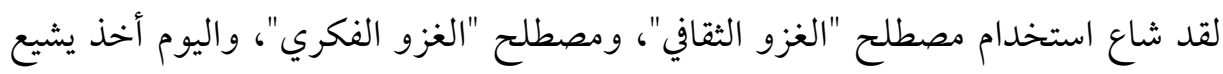

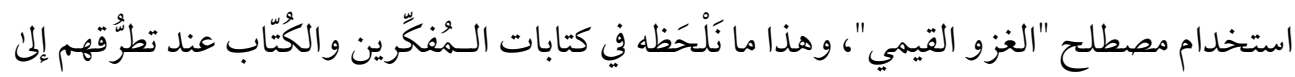

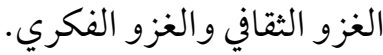

وعلنّ كلًّ، إذا كانت قيم المجتمع راسخة ومُتجذِّرة في سلوكات أفراده وأفعاهم، كما هو حال

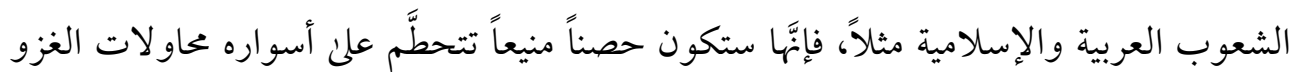
القيمي، والغزو الثقافي، والغزو الفكري. وهذا يدفعنا إنى القول بأنَّه يتعيَّن علن مجتمعاتنا العربية

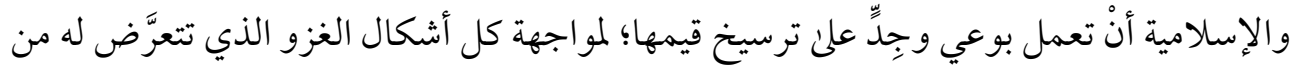
الدول العظمئ التي تسعئ جاهدة للهيمنة عليها ما استطاعت إلن ذلك سبيلاً.

\section{ثالثاً: تصنيف القيم}

اختلف الباحثون والدارسون في التوصُّل إلمن تصنيف عُحَّد للقيم وأنو اعها؛ ذلك أنَّ للقيم -في

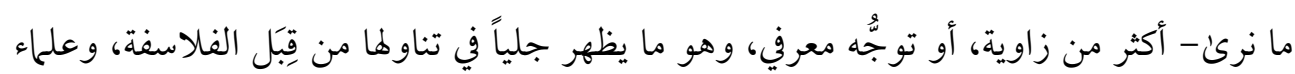
الاجتماع، وعلماء النفس، وغيرهم من علماء الاقتصاد والسياسة، هذا من جانب. ومن جانب آخر،

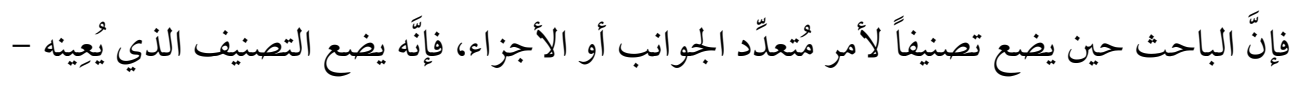

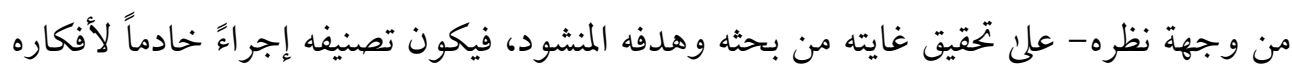

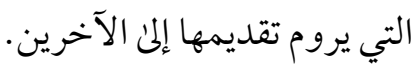

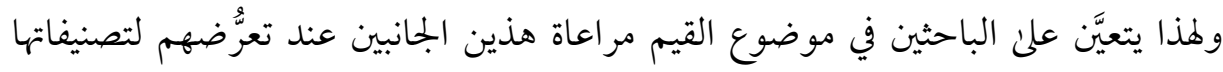

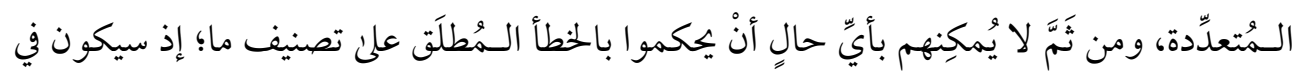

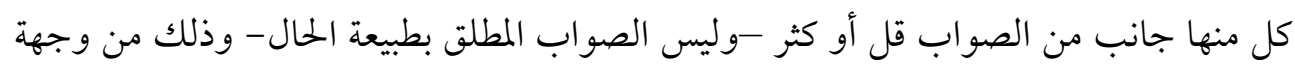
نظر مَنْ يتبنّاه طالما كان أداة معينة في بيان أفكاره وتوجُه مُاته وطرو حاته. ويُعَدُّ التقسيم الفلسفي التقليدي من أقدم التصنيفات العامة للقيم، وهو يتضمَّن ثلاث قيم كبرىن: الحق، والخير، والجحال. أمّا قيمة الحق فتدخل فيها قيم المعرفة الحقيقية، وقيم الوجود الحقّق. 
وأمّا قيمة الخير فتدخل فيها جميع القيم الأخلاقية علن مستوكن الفرد ومستوين الجماعة. وأمّا قيمة

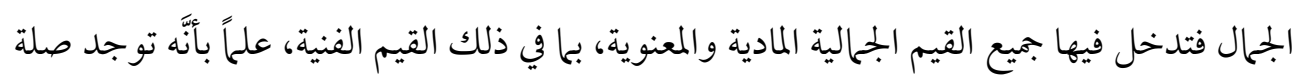
بين هذه القيم؛ إذ تُستخدَم في وصف بعضها لبعض، مثل قيم الخير التي توصَف أحياناً بأنَّا حقٌّ، أو

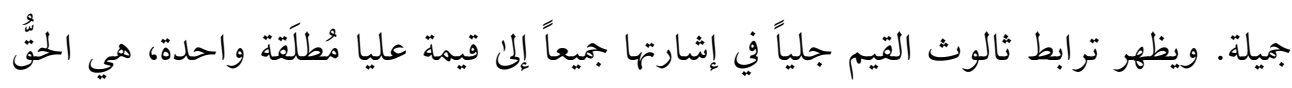

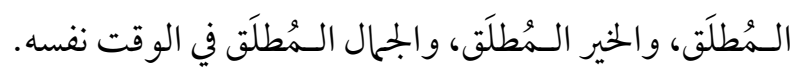

ومن التصنيفات الشائعة للقيم، تصنيفها بحسب الموضوعات التي تتعلَّق بها، فهناك قيم اجتماعية، وقيم اقتصادية، وقيم سياسية، وقيم أخلاقية، وقيم حقوقية (قانونية)، وقيم تربوية، وقيم دينية، وقيم جمالية، وقيم فنية، وغير ذلك من قيم الموضوعات والمجالات التي تزخر بها حياة الإنسان. ويو صَف هذا التصنيف بالأفقي؛ إذ تتساوين فيه جميع أنواع القيم، ولا يعلو أحدها على الآخر، وإنَّما هي أنواع قائم بعضها بجانب بعض. هرئ. والذين يقولون بهذا الرأي يرون أنَّ لكل مجال قيمه الخاصة، وأنَّ هذه القيم لا ينبغي لها أنْ تتعارض، أو تتصارع. غير أنَّ عدم التعارض أو التصارع بينها يشير إلن ضرورة هيمنة قيمة عليا تشارك فيها جميع القيم، وإلّا حدث الصراع، مثل تعارض قيمة فنية في أثناء تنفيذ عمل فني (مثل:

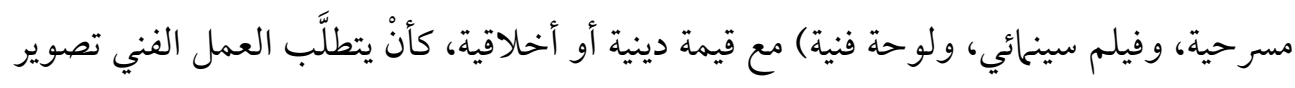
بعض المشاهد الإباحية. فهنا نكون أمام تعارض أو تصادم بين القيم، فعندئذِ، قد نتساءل: هل القيم الفنية لما علاقة بالقيم الدينية أو الأخلاقية أم لا؟ هل يتعيَّن في هذا العمل الفني الخالص أن تتحقَّق فيه القيمة الفنية في أوضح صورها؟ هل يجب تقديم القيم الدينية أو الأخلاقية علن القيم الفنية،

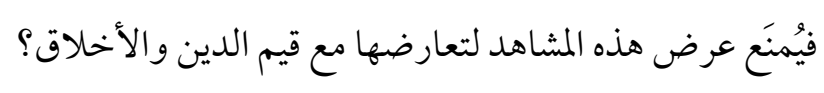

والشيء نفسه ينطبق علن قيم البحث العلمي حين يراد إجراء تجارب علن الحيوانات، أو علن الإنسان في بعض الحالات؛ إذ يتعارض ذلك (كلياً، أو جزئياً) مع القيم الأخلاقية، أو القيم الدينية.

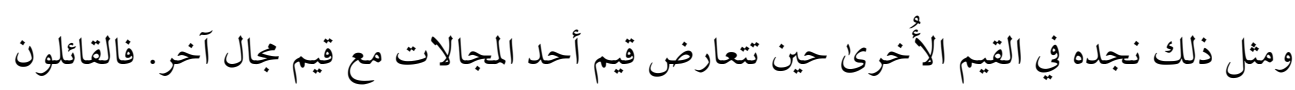

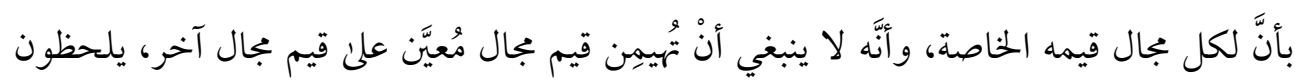




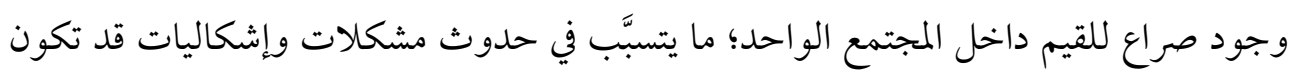

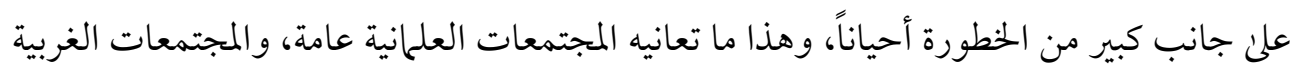
الحديثة بوجه خاص، ويظهر جلياً في النقاشات العديدة التي تدور حول القضايا المشار إليها آنفاً. إنَّ عدم وجود قيمة عليا عامة ومُهيمِنة يُرجع إليها لفضِّ التعارض والتصادم بين القيم

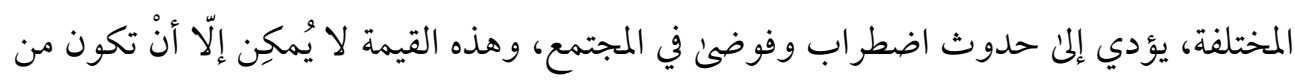

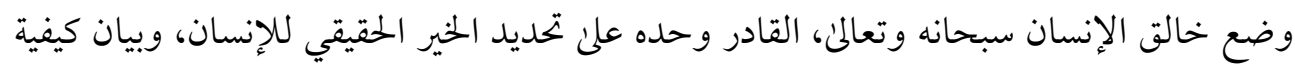

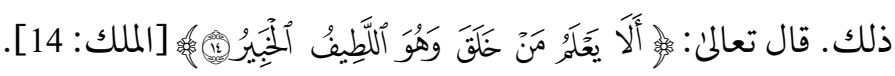
وفي المقابل، قد تُرتَبَ القيم ترتيباً عمودياً، أو رأسياً؛ ما يعني وجود قيم أدنئ أو أعلن من

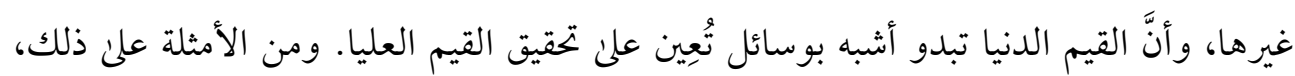

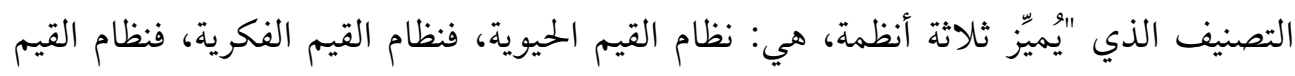

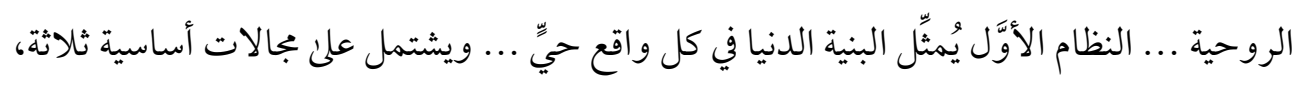

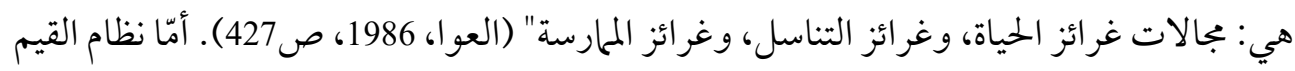

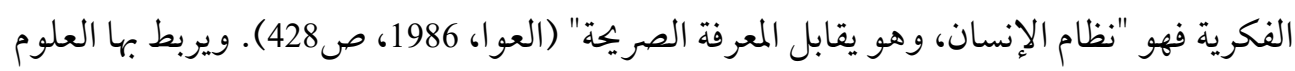

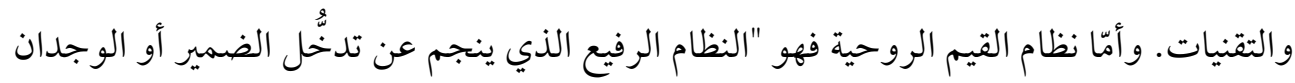

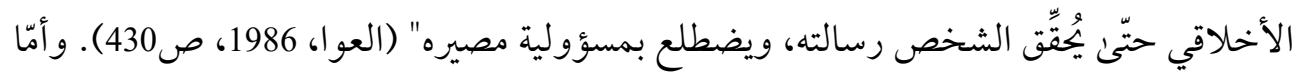

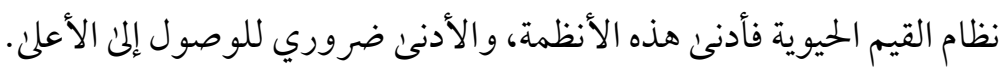
وتوجد تصنيفات أُخرى للقيم وضعها بعض علماء الاجتماع، وبعض علماء التربية، وبعض علم)ء النفس، وبعض الفلاسفة. (انظر عرض موسع لبعض هذه التصنيفات، العوا، 1986،

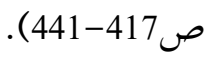

و الـمُلاحَظ علنم معظم هذه التصنيفات افتقارُها إلنا التأسيس الوجودي؛ أي عدم استنادها إنى

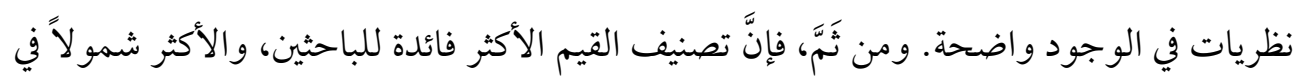

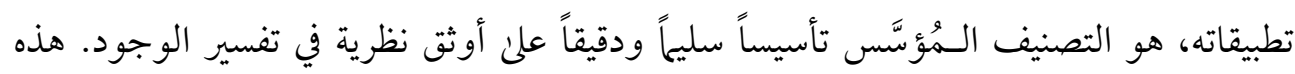


الملاحظة التي أوردنا هنا جعلتنا نساهم في وضع تصنيف للقيم يستند -فيا نرىن - علن أوثق نظرية

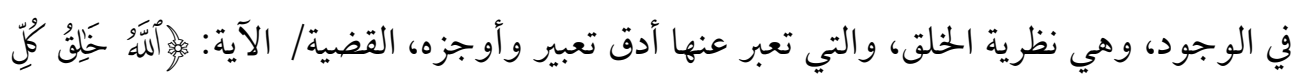

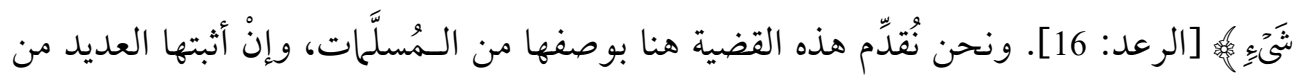

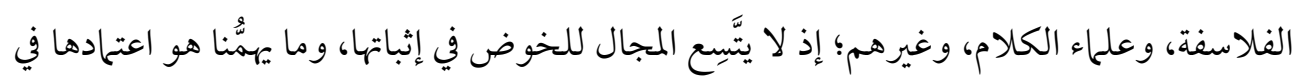

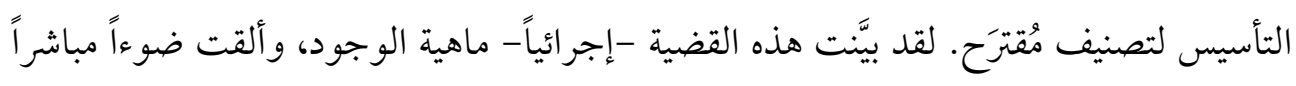
علن جانب عام جدّاً، لكنَّه -في الوقت نفسه - مُهِم جدّاً، وهو حقيقة هذا الوجود. إنَّ لفظ "وجود" هو من أعمّ الأوصاف؛ فلا يوجد وصف أعمٌّ منه ينطبق علن كل الأشياء الموجودة، وهذا اللفظ (أو الوصف) يُسمّن عند أهل المنطق جنس الأجناس، وهو لا يُعرَّف إلّا بنفسه، فنقول في تعريفه: الوجود وصف، يقال علن كل موجود؛؛ سواء أكان وجوده مادياً حسياً، أم

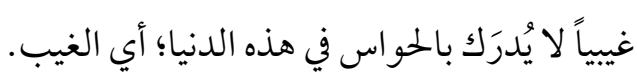

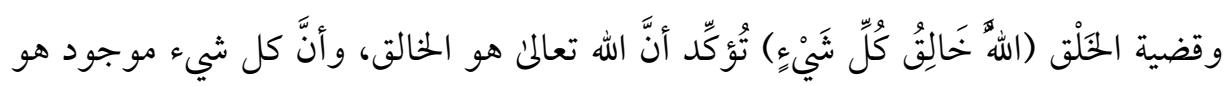

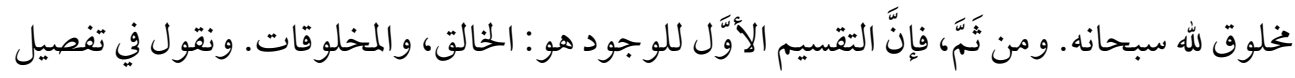

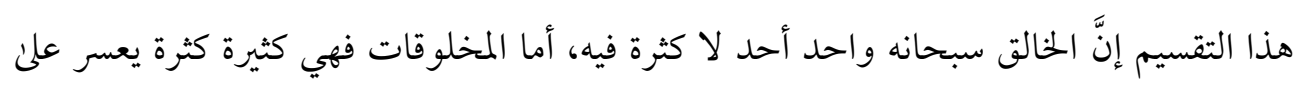
الإنسان إحصاؤها، إنْ لم يكن مستحيلاً، ولكنْ يُمكِن تصنيفها إلنى أقسام كبيرة واسعة، وقد قسَّمنا الوجود المخلوق إلن الأقسام الآتية: الذات الفردية أو الأنا، والآخر الذي يشمل الناس كافةً بخلاف

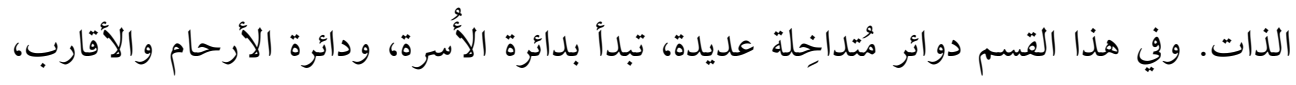
ودوائر الجوار والحي الواحد وجتمع البلدة وجتمع الدولة الواحدة، انتهاءً بالمجتمع الإنساني، ويشمل ذلك الأعداء والأصدقاء علن مستوى الفرد والمجتمع والدول. وكذلك يوجد الكون الطبيعي (السماوات، والأرض، ومَنْ فيهن)، وقسم الأفكار الذي تدخل فيه العلوم علن اختلافها، وتوجد أيضاً الأدوات والوسائل (المادية، وغير المادية)، و كذلك يوجد الزمان، والغيب. ومن هذه المخلوقات الإنسانُ الذي فضَّله الخالق سبحانه وتعالنُ علن كثير من خَلْقه. قال تعالن:

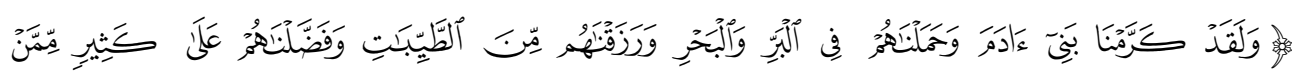




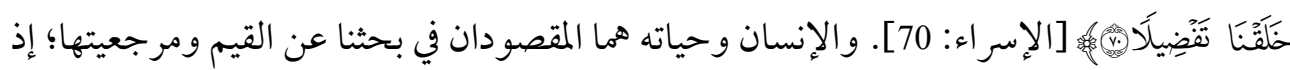
إنَّا ترتبط بالإنسان وسلوكه في الحياة في كثير من الجووانب؛ لذا سنذكر بعض المعلومات عن الإنسان وحياته؛ ما يساعدنا -إلن جانب ما ذكرناه آنفاً عن الوجود و أقسامه- علن التأسيس للتصنيف الذي لـي سنقترحه للقيم. لقد جعل الله تعالن الإنسان خليفة في الأرض، وهذا لا يعني -في نظرنا- أنَّه خليفة عن الله في

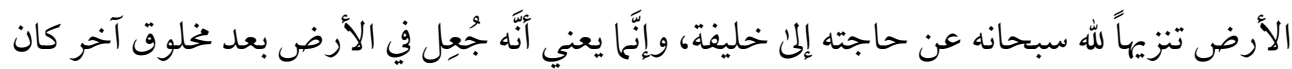
فيها،4 وأنَّه خُلِق ليؤدي مهمة على هذه الأرض، هي عهارتها. سلوك الإنسان في تحقيق الغاية التي خُحِق من أجلها، وهي عبادة الله سبحانه وتعالنا. وهذه الغاية

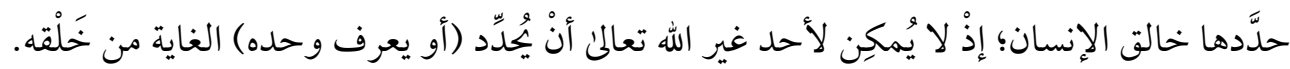

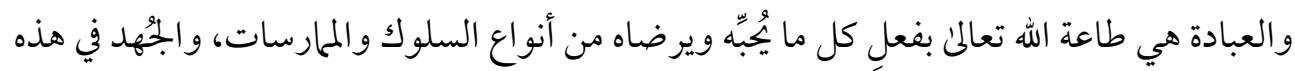
الطاعة (العبادة) يعود خيره إلنى الإنسان نفسه، لا إلن خالقه سبحانه غير المحتاج إلنا شيء؛ فهو الغني

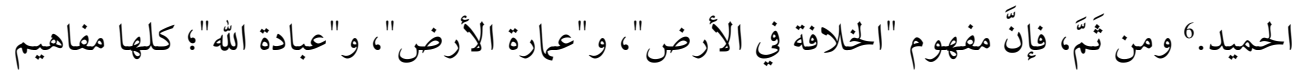
مُترابِطة ومُتكامِلة، ونتيجة تطبيقها هي تحقيق خير الإنسان، والوصول به إلن كمالاته اللائقة به بو صفه إنساناً.

أمّا الحياة الإنسانية فهي حركة الإنسان في تعامله مع جوانب الوجود كلها (الخالق، والمخلوقات)؛ ذلك أنَّهَ يتعيَّن علن الإنسان أنْ يتعامل مع كل أجزاء الوجود؛ طوعاً أوكرهاً،

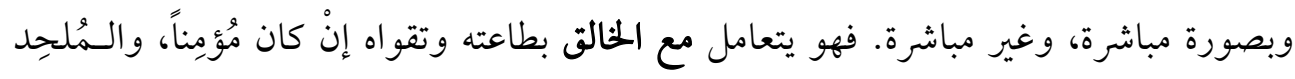
يتعامل مع الله بإنكار وجوده وخَلْقه لكل شيء. والإنسان يتعامل مع المخلوقات؛ فيتعامل مع ذاته

4 4 السياقات التي وردت فيها ألفاظ "خلف"، و"استخلف"، و "خلافة" في القرآن الكريمتُؤَّدّد هذا المعنى.

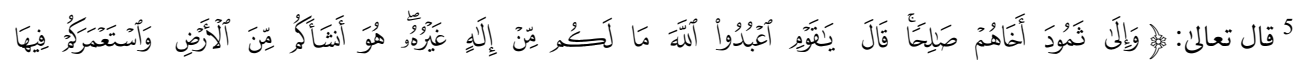

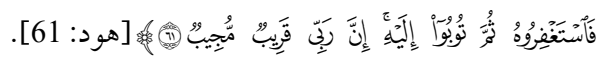

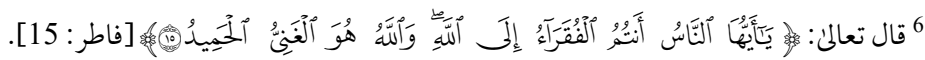


بالحفاظ علن وجوده وكيانه؛ فيتعامل مع الآخر -في أدنى الأحوال- في دائرة الأُّرة، وفي الدوائر الاجتماعية الأخرىن؛ وكذلك يتعامل مع الكون الطبيعي؛ الأرض وما عليها، والسماء وشمسها وقمرها، بها في ذلك إعمار الكون؛ وهو يتعامل أيضاً مع الأفكار بغَضِّ النظر عن تحصيله العلمي، بها في ذلك الأخبار علن اختلاف أنو اعها؛ وكذلك يتعامل مع الأدوات والوسائل التي يستعين بها على

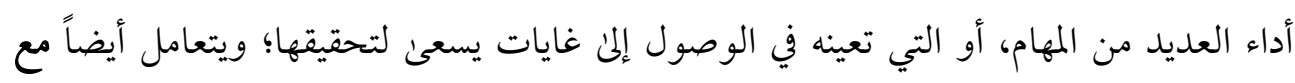
الزمان، إذ يُنظّم أوقات أنشطته، ومراحل حياته؛ وكذلك يتعامل مع الغيب الذي يُنكِره السمُلحِدون، بالرغم من وضوح وجوده؛ ذلك أنَّ كُنه الإنسان -في مبدئه - غيب، ومآله غيب، وهو جزء صميم في وجودنا؛ أي الروح أو النفس، وعِلَّة وجود هذا العالَّ غيب كذلك. وتجاهل الإنسان الغيب يجعل حياة الناس والمجتمعات قريباً من حالة الحيوانات في الغابة؛ فالغيب موضوع إيهان، ويترتَّب علن هذا الإيهان سلو كات إيجابية.

و الخلاصة أنَّالإنسان يتعامل مع كل أجزاء الوجود، ويهارس أشكالاً من السلوك لا حصر ها في أثناء حياته، وهنا نقترب كثيراً من فكرة ضرورة وجود القيم في حياة الإنسان، واستنباط تصنيف لها مُؤَسَّ تأسيساً وجودياً راسخاً؛ فالقيم ما هي إلّا معايير نحكم بها على أنواع السلوك الإنساني بالصواب أو الخطأ، وبالحق أو الباطل، وبالخير أو الشر، وهي تُمثّل -بصورة ما- الحالة المثلن التي ينبغي أنْ يكون

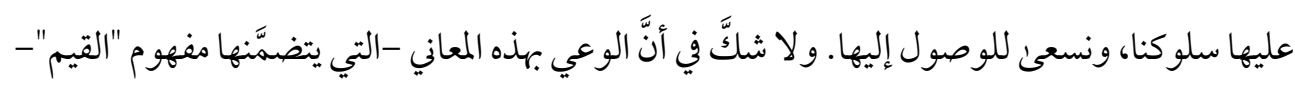
يُعَدُ حافزاً لدى الإنسان للقيام بالسلوك الذي يتجه نحو الوصول إلن هذه الحالة المثلن.

وإذا كان الأمر كذلك، فإِنَّ لكل شكل من أشكال السلوكات -مع جوانب الوجود- قيماً (بالوصف السمُتقدِّم لمفهومها) ثُناظِر قسماً من أقسام الوجود؛ ما يعني وجود قيم للتعامل مع الخالق سبحانه وتعالن، وقيم للتعامل مع المخلوقات. ولهّا كانت جوانب الوجود المخلوق (المخلوقات)

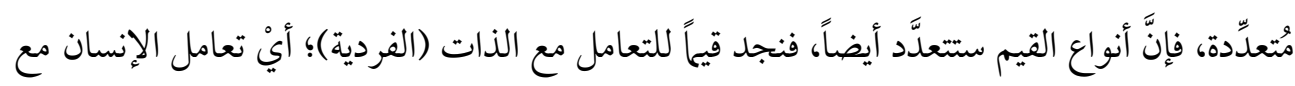
نفسه، وقياً لتعامله مع الآخر في جميع الدوائر الاجتماعية، وقيماً لتعامله مع الكون الطبيعي، وقياً لتعامله مع الأفكار، وقياً لتعامله مع الأدوات والوسائل، وقياً لتعامله مع الزمان، وقياً لتعامله مع الغيب. 


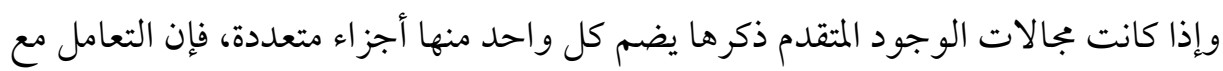
هذه الأجزاء ستكون له قيم متعددة بعدد هذه الأجزاء، فيكون هناك قيم فرعية للقيم العامة (الخاصة بكلٍّ من المجالات الكبرىن المذكورة آنفاً)، و كذلك وجود قيم فرعية لكلٍّ من قيم المجالات الكبرى،، ونقترح أنْ نُسمِّها جميعاً عائلات القيم، ومن ثَمَّ يكون لدينا عائلة القيم في التعامل مع الخالق، وعائلة القيم في تعامل الفرد مع ذاته، وعائلة القيم في التعامل مع الآخر (في الدوائر المختلفة)، وعائلة القيم في التعامل مع الكون الطبيعي، وعائلة القيم في التعامل مع الأفكار، وعائلة القيم في التعامل مع الأدوات والوسائل، وعائلة القيم في التعامل مع الزمان، وعائلة القيم في

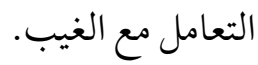

إن تصنيف القيم إلن هذه العائلات يُسهِّل أمر النظر في تفاصيل كل عائلة منها، والتعرُّف علن القيم الفرعية فيها، علماً بأنَّ عائلات القيم هذه تشمل -في نظرنا- جميع جوانب السلوك الإنساني في الحياة (الدنيا).

وهذا التصنيف للقيم يقوم علن صلتها بالتعامل مع الوجود، ويمكن أن نُسمّيه: تصنيف القيم بحسب أقسام الوجود، وتوجد تصنيفات أُخرى يُمكِن إلحاقها بهذا التصنيف، بوصفها جوانب جزئية منه، مثل تصنيف القيم بحسب الموضوعات؛ أيْ تصنيفها إلن قيم اقتصادية،

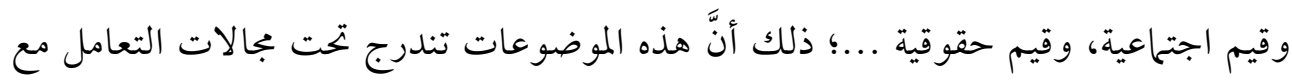

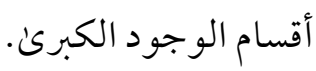

صحيحُ أنَّ هذا التصنيف كشف عن وجود قيم مُتنوِّعة ومُتعدِّدة بالتناغم مع تنوُّع أقسام

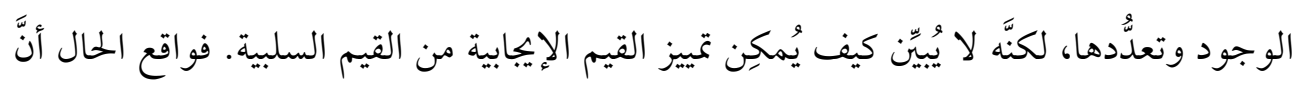

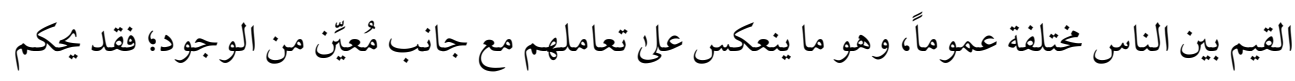
البعض بأنَّهُ يُمثّل قيمة إيجابية، في حين يهكم البعض الآخر بأنه قيمة سلبية. ومن هنا يحدث التصادم و التعارض بين القيم المتبنَّة من الأطر اف المختلفة، وقد يؤول الحال إلن صراع مادي واقتتال بين هذه بئه 
إنَّ هذا الاختلاف في تقييم السلوك الواحد (أيْ قيم التعامل مع الوجود وأجزائه) مردُّه

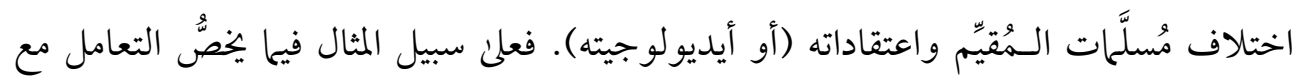
الخالق، نجد أنَّ قيم السموّوِن تختلف عن قيم السمُلحِد في هذا الجانب. وكذلك الحال بالنسبة إلنا تعامل الفرد مع ذاته؛ فقيم من يعتقد أن الإنسان مرُكَّب مادي فقط، مختلفة عن قيم من يركن أنَّه روح

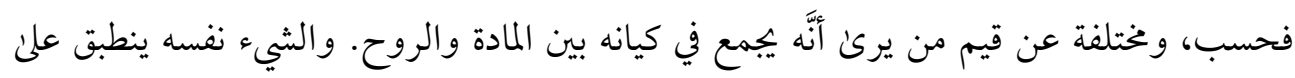

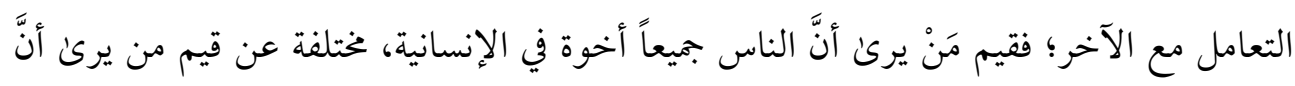

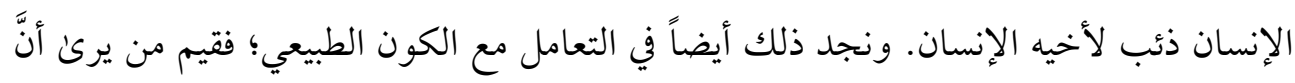
الكون مُسخَّر للإنسان، مختلفة عن قيم من يركن أن الكون عدوُ أو خصمّ يتعيَّن قهره، و السيطرة

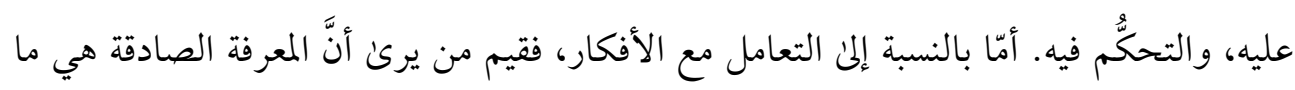

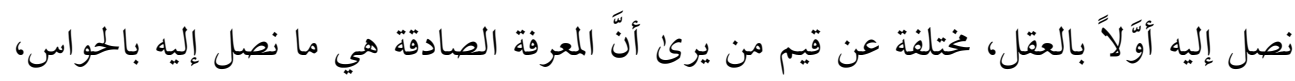

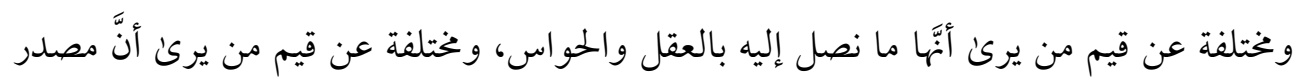
المعرفة الصادقة الرئيس هو الوحي الإلهي، ونختلفة عن قيم مَنْ يرىن الجمع بين كل هذه الوسائل.

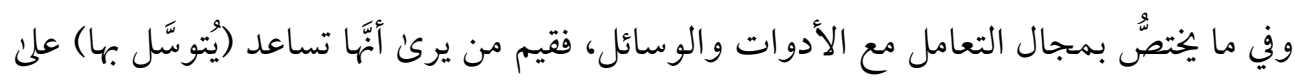
تسهيل حركة الحياة وحركة العمران، مختلفة عن قيم من يجعلها غاية في ذاتها. وفي بجال التعامل مع الزمان، فقيم من يركن أنَّ للزمان أهمية في تنظيم شؤون الحياة وأنشطتها وتحديد الأولويات فيها، خختلفة عن قيم من لا يكترث بالزمان، ويغفل عن أهميته في الحياة الإنسانية. أمّا بخصوص التعامل

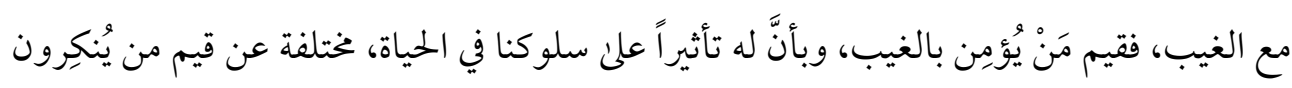
وجود الغيب، أو يتجاهلونه.

إنَّ اختلاف القيم الـمُتقدِّم وصفه هنا لا يِجعلنا نُقبِل عليه ونحن مُسلِّمون به؛ فإنبّا في القيم نبحث عَّا يجب أنْ يكون؛ ما يُحتِّم علينا تعرُّف القيم الإيجابية وتمييزها من القيم السلبية، ويساعدنا علن ذلك الفكرة التي يعتقد بها جميع الناس (تقريباً)، وهي تقسيم سلوك الأشخاص وأعمالهم إلنا

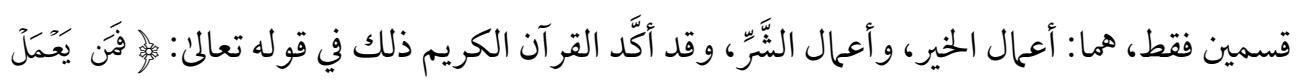




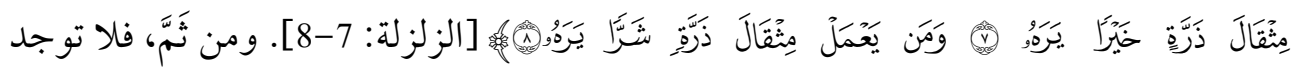

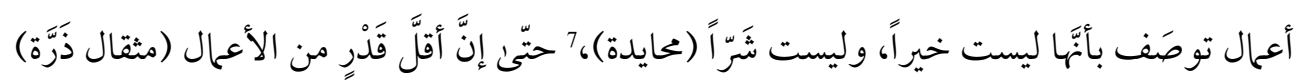
يو صَف بالخير أو الشَّرّ.

لقد أشرنا آنفاً إلمن أنَّ تصنيفنا الهُمقترح للقيم (تصنيف القيم بحسب أقسام الوجود) لا يُبيِّن

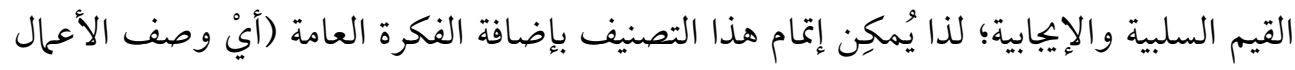

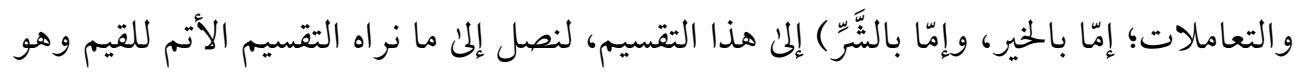

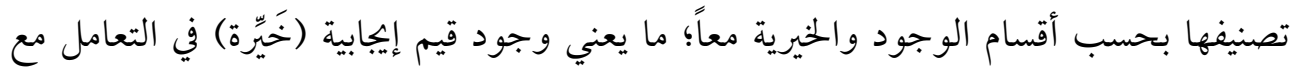

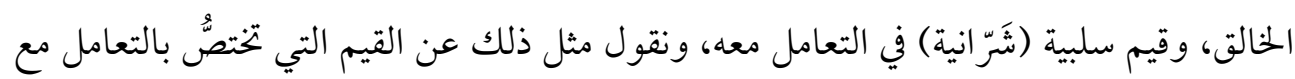

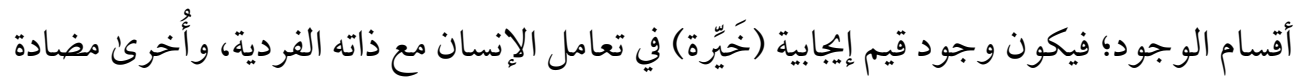

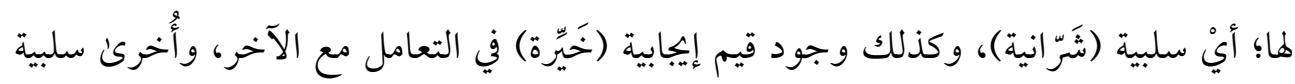

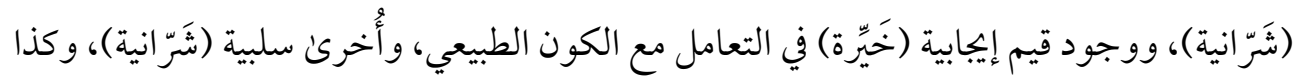

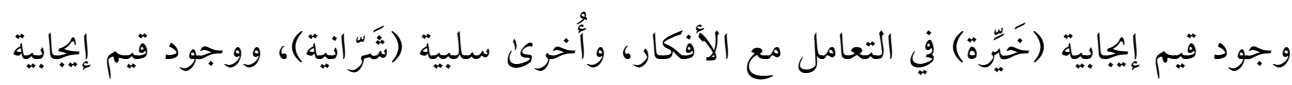

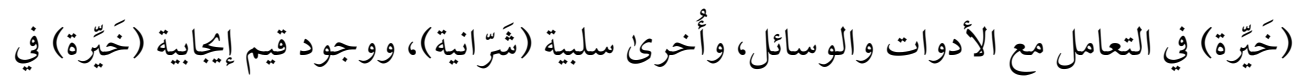

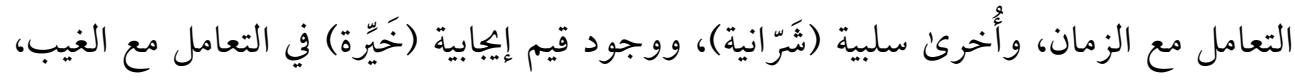
وأُخرى سلبية (شَرّا انية).

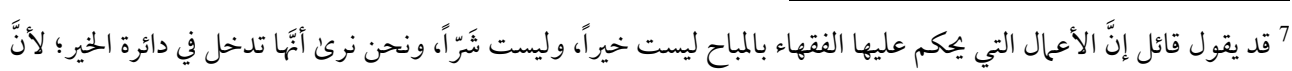
الذي أباح فعلها أو تركها هو الله سبحانه وتعالن، فتلخل - بالضرورة - في دائرة الخئر. 

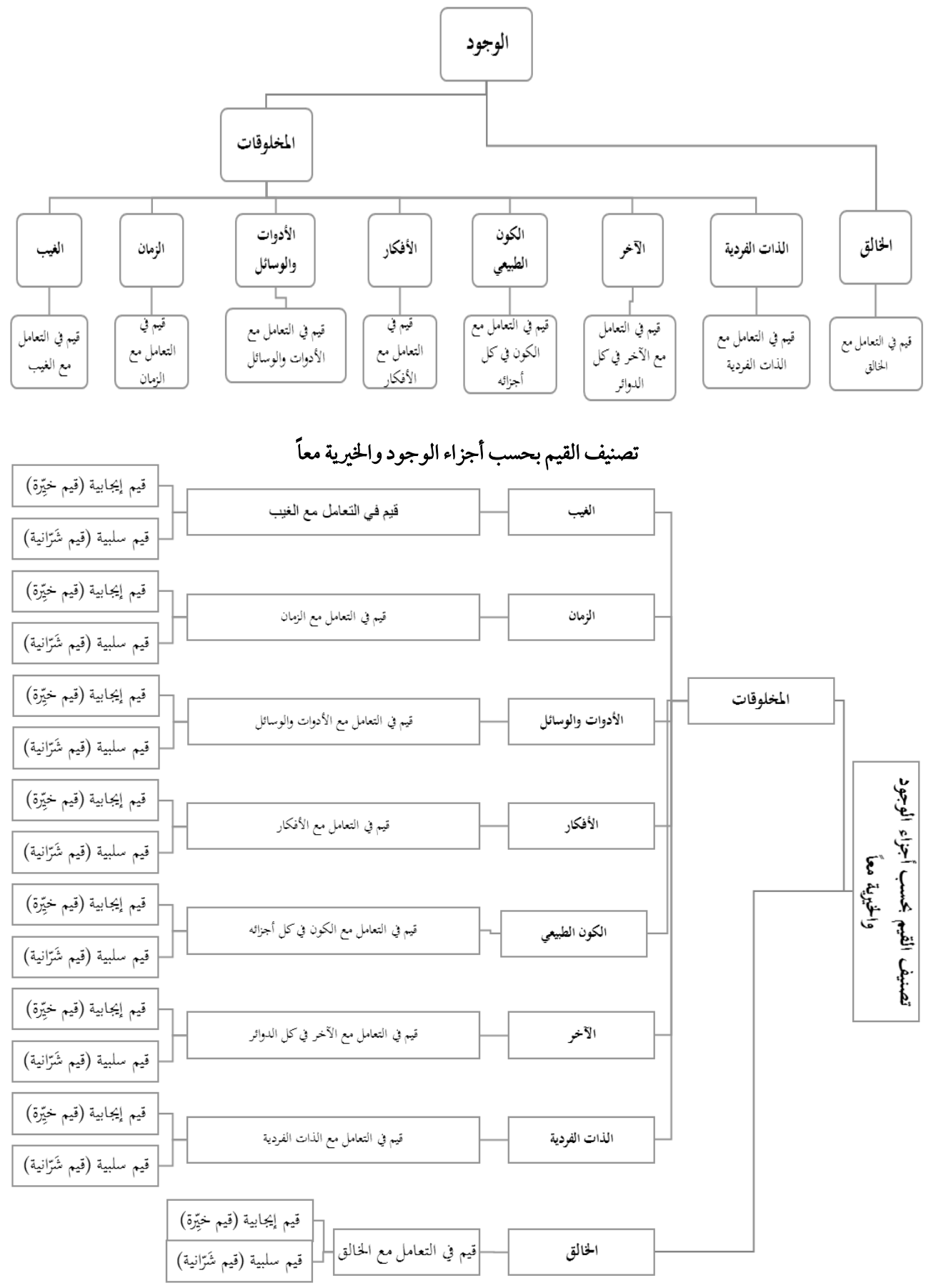


\section{رابعاً: مصدر القيم والقيم الإيجابية (الحِيّرة)}

تُمثّلّ هذه المسألة إحدى قضايا فلسفة القيم لدئ الباحثين والفلاسفة الذين تعرَّضوا لبحث

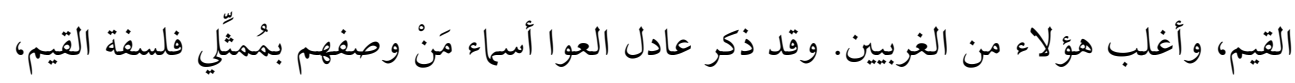

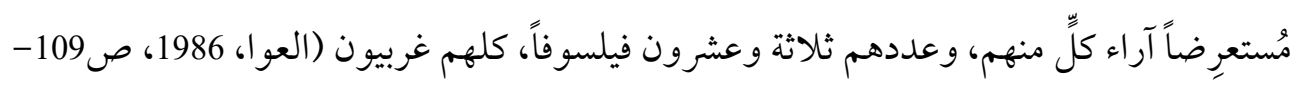

وفي ما يأتي ملخص للآراء البارزة حيال مصدر القيم عامة عند هؤلاء الباحثين، يليه اجتهادنا

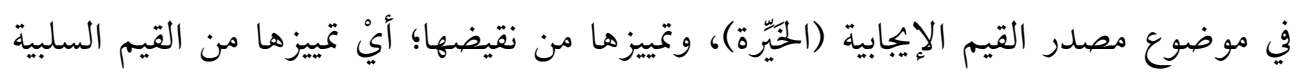
(الشَّرّانية).

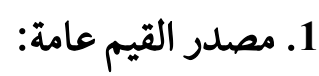

يرئ الباحثون في فلسفة القيم أنَّ هذا المصدر هو أحدُ اثنين؛ إمّا أنْ يكون الإنسان مصدر القيم وواضعها ومُؤسِّها، وإمّا أنْ يكون الله سبحانه وتعالنم مصدر القيم كلها.

وهذا ما أوضحه أحد الفلاسفة الذين بحثوا في موضوع القيم، وهو لويس لافيل Louis Lavelle

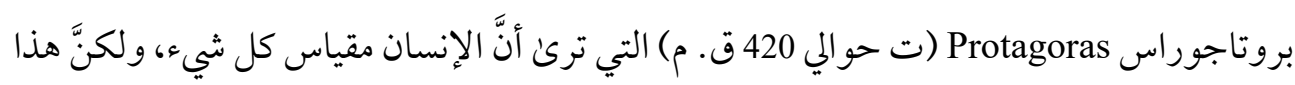

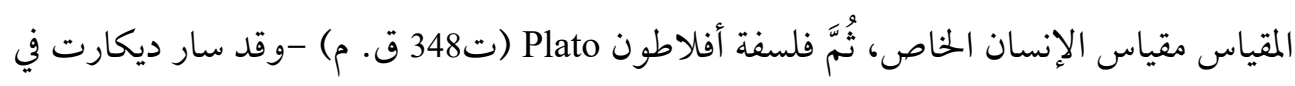

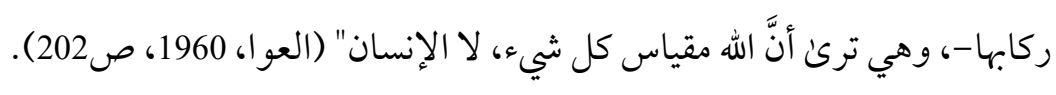

ومِنَ الذين قالو ا بالر أي الأوَّل، نيتشه F. Nietzsche (ت 1900م) الذي أرجع أصل القيم

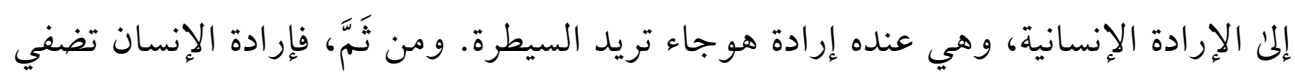

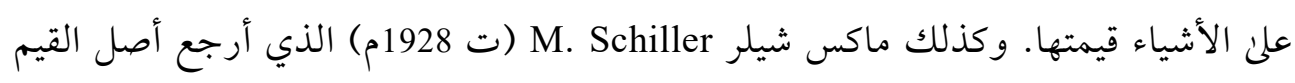
ومصدرها إنن حدس عاطفي انفعالي؛ أي العاطفة التي تهتم بالترجيح بين الأشياء والأمور 
وفي المقابل، نجد مَنْ ربطوا القيم -في مصدريتها - بالنجاح العملي في الحياة الإنسانية، وهؤلاء هم البرجماتيون عامة، والذرائعيون بوجه خاص. أمّا علماء الاجتماع عامة فأرجعوا أصل القيم ومصدرها إنن الحياة الاجتحاعية والمجتمع؛ فاجتماع الناس وضرورات الحياة الاجتماعية هي التي توجد القيم المختلفة لتنظيم أمور المجتمع. إنَّ القول باعتبار الإنسان مصدر القيم؛ سواء أكان فرداً أم جماعةً، يؤدي بالضرورة إلن القول بنسبية القيم وَفقاً لأحوال الإنسان وظروف حياته وعصره، ويؤدي كذلك إلن القول بعدم ثباتها وتغيُّرها بتغيُّ الظروف والأحوال؛ ما يحول دون ظهور منظومات قيمية متنَِّقة، وغير مُتعارِضة، أو غير مُتصارِعة. أمّا بالنسبة إلى الر أي الآخر الذي يُرجِع مصدر القيم إلن الله سبحانه وتعالنا، فإنَّ من القائلين به أفلاطون الذي جعل اله هو المثال الأعلى (مثال الخير)، ورأين أنَّ كل الأشياء تستمد قيمتها من

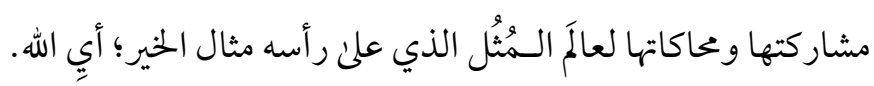

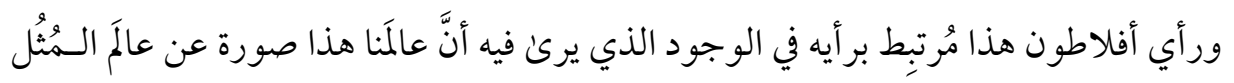

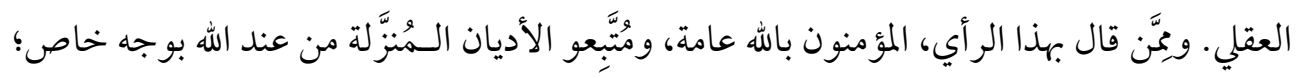

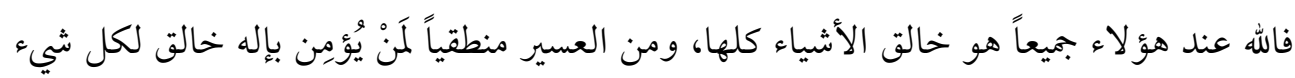
وخالق للإِنسان ألّا يُرجِع مصدر جميع القيم إلن الله سبحانه وتعالن. نتتقل -بعد هذا العرض السمُختصَر لمصدر القيم عند الغربيين- إلمن عرض اجتهادنا في بيان مصدر القيم الإيجابية (الخيّرة).

\section{2. مصدر القيم الإيجابية (الحِيّة)):}

بو جه عام، فإنَّ مطلب الإنسان في حياته هو السعي لتحقيق خيره في هذه الحياة. وهذا المطلب

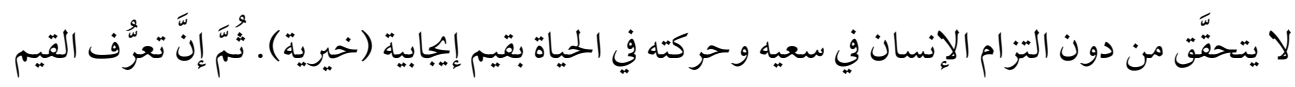
الإيجابية (الحِّرّة) يحتاج إلى تعرُّف مفهوم "الخير" ومصدره، الذي إذا أضفناه إلن مفهوم "القيم" سهَّل

$$
\text { علينا تمييز القيم الإيجابية (الحيّرة) من القيم السلبية (الشَّرّانية). }
$$


ونبدأ مُذكِّرين بالأساس الوجودي الأوَّل (الله خالق كل شيء)؛ أيْ وجود خالق ومخلوقات،

ومنها الإنسان، وأنَّنا نبحث عن خير الإنسان، لنطرح بعد ذلك السؤال الآتي: مَنِ الذي يُحِّدّد للإِنسان خيره؟

فيجاب عن المطروح بثلاث إجابات مُحتمَلة: الإنسان نفسه، أو مخلوق آخر -من بين مخلوقات

$$
\text { الله التي لا حصر لها- غير الإنسان، أو خالق الإنسان. }
$$

والذي يساعدنا علن الإجابة عن هذا السؤال، ويُحِّد لنا الاحتحال الأقرب من هذه

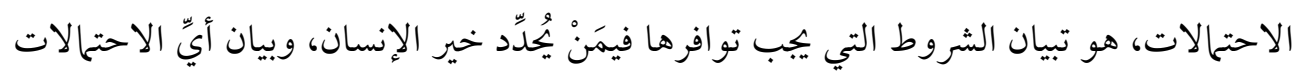
الثلاثة تتحققّ فيه هذه الشروط.

إنَّ أوَّل هذه الشروط -في نظرنا- هو أن الذي يُحدِّد للإنسان خيره لا بدّ أن يعرف حقيقة الإنسان من كل جوانبه على أكمل وجه، وثاني هذه الشروط هو أن يعرف علن الوجه الأكمل حقيقة الوجود الذي يتعامل الإنسان مع كل أجزاءه؛ ذلك أنَّ أفعال الخير التي توصف بل بالخير، أو أفعال الشَِّّ لا تكون إلّا في بيئة اجتماعية وكونية. أمّا الشرط الثالث فهو اتِّصافه بالكمال الـمُطلَق من كل وجه؛ حتّى يكون مُنََّّهاً عن الحاجة، و الهوكن، والمصلحة الشخصية، وخالياً من كل نقص؛ أيْ يكون خيراً مُطلَقاً. و إذا نظرنا في هذه الشروط الثلاثة، فإنَّنَا نَلْحَظ أنَّها لا تتحقَّق إلّا في خالق كل شيء (أي الله سبحانه وتعالن)؛ ذلك أنَّه لا يُمكِن للإِنسان أو لأيّ مخلوق آخر أنْ يعرف حقيقة الإنسان على الوجه الأكمل -وهذا واضح في واقع الحال بالنسبة إلن الإنسان- فقد اكتسب علن مرِّ العصور معرفة غير

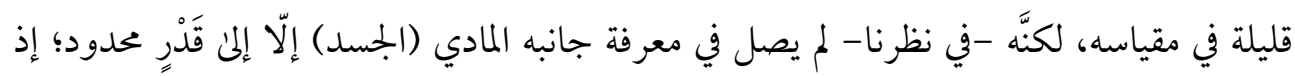
يكتشف كل يوم نَزْراً يسيراً من هذا الجانب المادي، فكيف بعلمه حقيقة الجوانب غير المادية في كيانه؟! ومثل ذلك يقال عن معرفة الإنسان بالوجود الطبيعي، والوجود الغيبي. وقد أكَّد القرآن

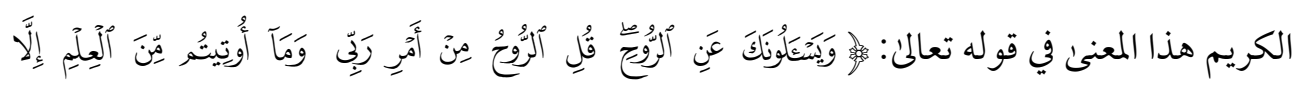

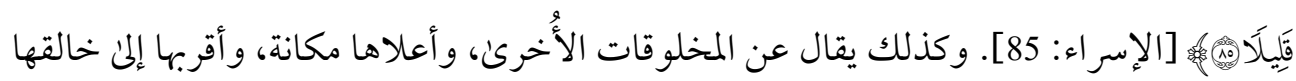




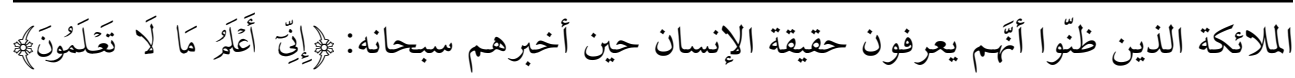

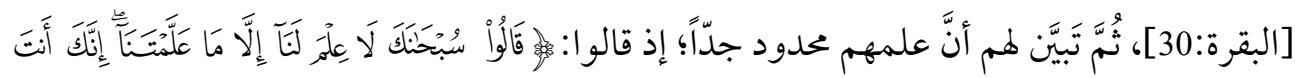

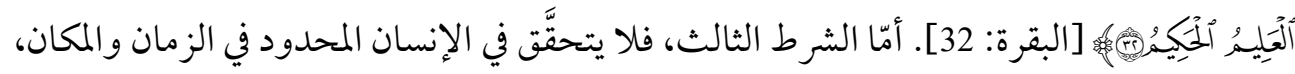

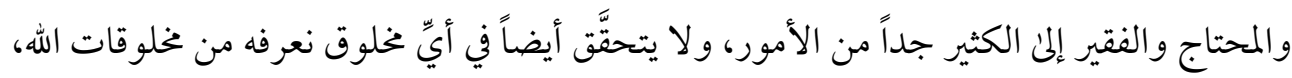

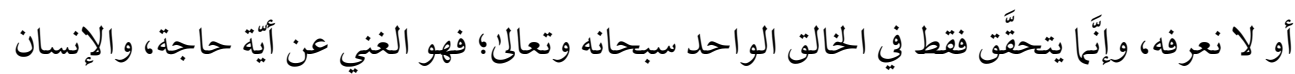

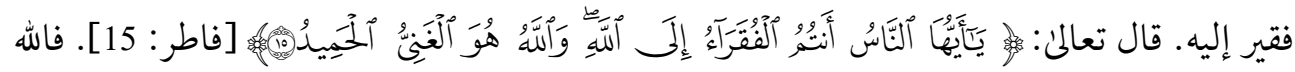

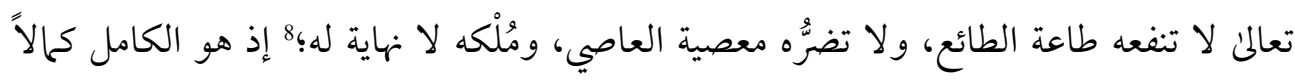
مُطلَقَاً. وهكذا نصل من الـمُقدِّمات المذكورة آنفاً إنى إجابة السؤال الذي طرحناه عن واضع الخير للإنسان؛ فهو الله خالق كل شيء، وخالق الإنسان. أمّا السؤال الآتي الذي يتوارد إلم الذهن: كيف نعلم تفاصيل هذا الخير وأشكاله؟ فجوابه المعلوم عند الـمُؤمِنين بوجود الله هو عن طريق الوحي الذي نزَّله سبحانه علن رُسُسله، وعن طريق

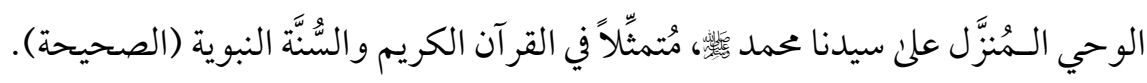
وبالرغم من هذا الاستدلال الذي قدَّمناه هنا، فإِنَّه يوجد مَنْ يعتقدون بأنَّ الإنسان قادر بعقله وقدراته أنْ يُحِّد ما هو خير له من دون حاجة إلن العون الإهلي (الوحي). ونردُّ علن هؤلاء بالقول لقد قام الإنسان بتحديد ما هو الخير له بنفسه، ولكنْ من دون وجود تحديد مُتَّقَق عليه؛ إذ توجد اختلافات كثيرة بهذا الخصوص. ودارسو علم الأخلاق الفلسفي يعلمون عدد المذاهب الأخلاقية التي تتباين في هذا الشأن، ومنها: مذهب اللذَّة، ومذهب المنفعة، ومذهب الحاسَّة الخلقية، ومذهب الخب

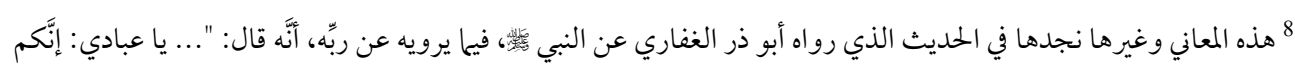

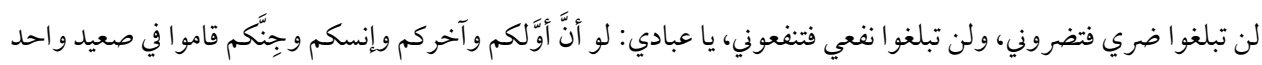

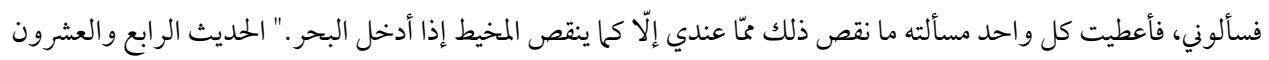

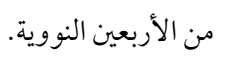


الضمير، ومذهب الواجب، والمذهب البرجماتي، ومذهب العلاقات الحميمة، وغيرها، وكلّ له رأيه

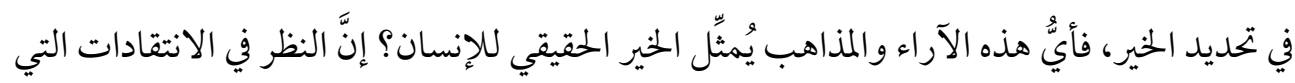

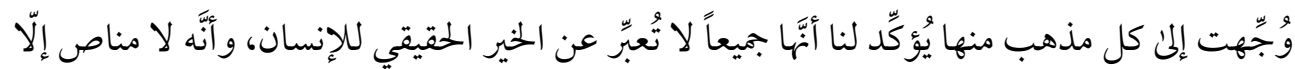

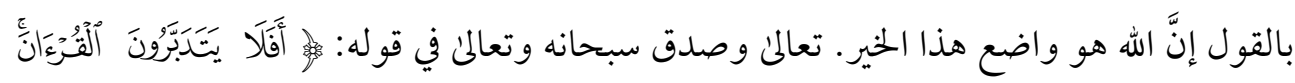

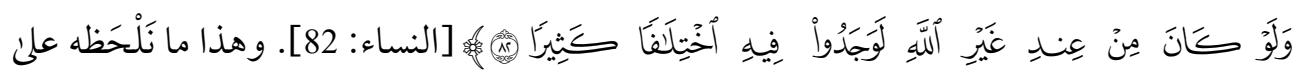

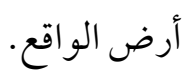

ويتَّصِل بهذه المسألة -في ما نرىن- موضوعُ تحدَّث فيه العديد من الفلاسفة والـهُفكِّرين، وهو

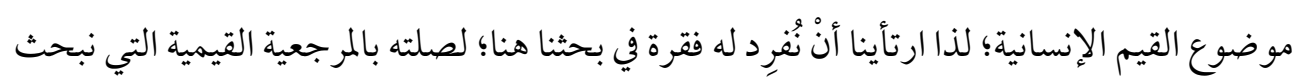
عنها للتعليم الجامعي.

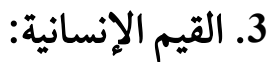

لن ندخل هنا في تعداد القيم الإنسانية، وحسبنا الاجتهاد في بيان خصائص هذه القيم، والشروط التي إذا توافرت في قيمة ما حكمنا بأنَّا إنسانية، وإلّا حكمنا -بكل اطمئنان- بأنَّا غير إنسانية. وهذه الشروط تتمثَّل في المعاني الآتية بُجتمِعةً:

أ. الإنسانية -كوصف لفعل أو سلوك- بمعنى أنه يُلائم فطرة الإنسان، أي ما ركب فيه من

غرائز واستعدادات وُلِد بها، ويساهم في وصوها إلن كمالاتها؛ فالسلوك الذي يَقمع غريزةً أو استعداداً فطرياً هو سلوك غير إنساني. فمثلاً، الحاجة إلم الطعام غريزة. ومن ثَمَّ، فالتجويع الـمُتعمَّد سلوك غير إنساني. ومن أمثلة الاستعدادات: الاستعداد للتعلُّم؛ فالتعلُّم وكل ما يُيسِّره للناس سلوك إنساني، و التجهيل سلوك غير إنساني. وهكذا حال جميع الاستعدادات التي يولَد بها الإنسان. ويجب الانتباه هنا إلنا أنَّ هذه السلو كات لا تكون إنسانية إذا لم تَّكمها ضو ابط، وهذا وهذا يشمل الغرائز والاستعدادات. - مات. 
ب. الإنسانية -كوصف لفعل أو سلوك- بمعنى أنه يؤدي إلى المحافظة علن الوجود الإنساني -

علن مستوى الفرد ومستوئ الجماعة- بحيث يقود الإنسان باتجاه تحقيق كماله اللائق به كإنسان؛ فما كان كذلك فهو إنساني، وإلّا فهو غير إنساني. فأفعال مثل: الصدقة، وإغاثة الملهوف، وكفالة اليتيم، و إطعام الطعام، وإفشاء السلام، وما شاكلها؛ كلها تُسهِم في الحفاظ على الوجود الإنساني وبقائه، أو تكميله وترقيته والسمو به، ليصل إلنى درجة عليا بو صفه إنساناً. وفي المقابل، فإنَّ أفعالاً أُخرى مثل: القتل، والاعتداء بالتعذيب، والسرقة، والغشّّ، واحتكار السلع، وأكل مال اليتيم، والرشوة، وما

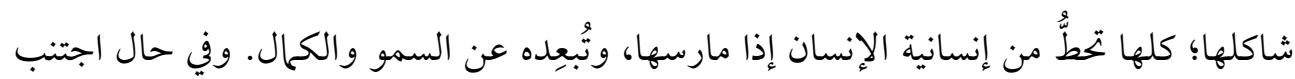
الإنسان هذه الممارسات والأفعال السلبية كان هذا الاجتناب سلوكاً إنسانياً. تـ الإنسانية -كوصف لفعل أو سلوك- بمعنى أنه يُلائم الناس كافةً علن اختلاف أجناسهمه، وألو انهم، وأنسابهم، ولغاتهم، فضلاً عن اختلاف عصورهم وأماكنهم، ويهتمّ بمصالحهم جميعاً في

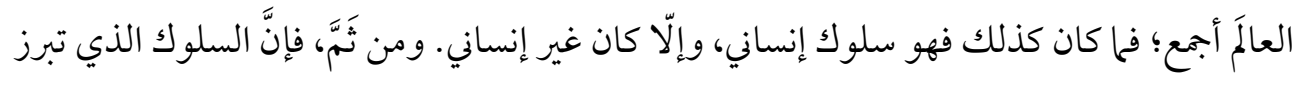
فيه الأنانية؛ سواء علن مستوىن الفرد، أو علن مستوى المجتمع والدولة، هو سلوك غير إنساني. أمّا السلوك الذي يظهر فيه الإيثار؛ سو اء أكان ذلك علن مستوكن الفرد، أم علن مستوىن الجماعة، فهو

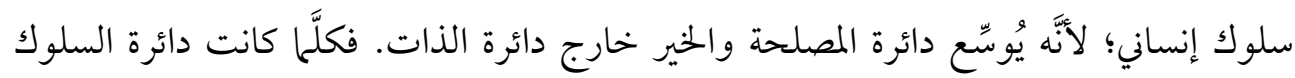
الخارج عن نطاق الذات أكبر وأوسع كانت درجة إنسانيته أكبر. ث. الإنسانية -كوصف لفعل أو سلوك- بمعنى أنه يجعل الإنسان -كل إنسان وأي إنسان-

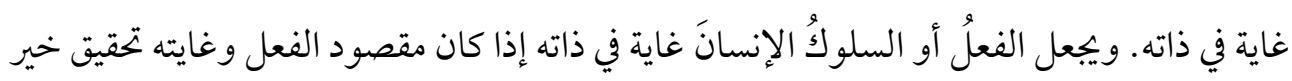
الإنسان ومنفعته الحقيقية. أمّا إذا نظر الفعل أو السلوك إلن الإنسان بوصفه وسيلة لغاية أُخرىن

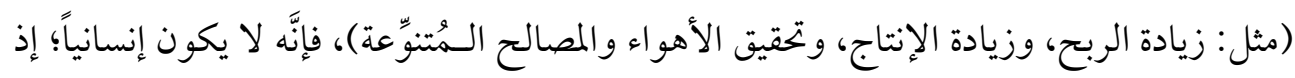
الإنسان في سياقه وسيلة. فمثلاً، إجراء تجارب علن الإنسان لاختبار قدرة سلاح ما، أو معرفة ما يترتب علن استخدامه من نتائج هو سلوك غير إنساني؛ لأنَّ الإنسان هنا عومِل فقط بوصفه وسيلة؛ الإِ سعياً للو صول إلى غايات أخخرىن. 
إنَّ هذه الشروط بُجتمِعة -في ما نرىن - يجبَ أنْ تتحقَّق في أيّة قيمة حتّى تكون إنسانية 9 (السيد

$$
\text { أحمد، 2015، ص 69-105). }
$$

أمّا بالنسبة إلن عالاقة القيم الإنسانية بالقيم الخَيِّة أو القيم الإيجابية، فمن غير الـمُمكِن وجود قيمة إنسانية تتحقَّق فيها الشروط السابقة، ولا تكون قيمة خَيِّة (إيجابية)؛ فالقيم التي

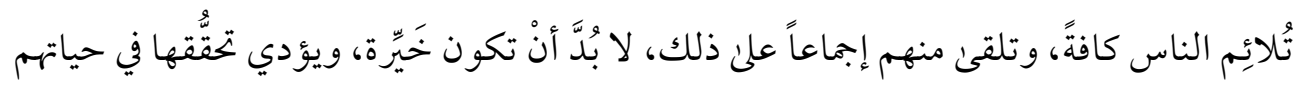
إلى تحصيل الخير لهم.

ولهّا كانت القيم الخَيِّة (الإيجابية) من وضع الخالق سبحانه، فإنَّ القيم الإنسانية بالشروط الـمُتقدِّمة- لا يضعها (أو يُحِدِدها) الإنسان، وإنَّما يضعها خالق الإنسان الذي يعلم مَنْ خلق. ويؤَيِّد هذا الر أي اختلاف الناس في تحديد القيم الإنسانية، وتحديد شروطها، مصداقاً

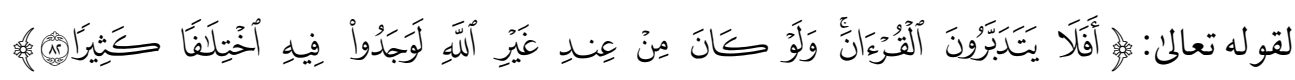
[النساء:

وهذه النتيجة تنقلنا إلنا مسألِّة ما ينبغي أنْ تكون عليه القيم الخيّرِة الإيجابية والقيم الإنسانية، من حيث الثبات أو التغيُّ، ومن حيث الإطلاق أو النسبة.

\section{خامساً: القيم من حيث هي نسبية أو مُطلَقة}

إنَّ القول بنسبية القيم يعني أنَّا تصلح لظروف وأحوال مُتنغيّرة، أو تناسب فقط أناساً، أو بحتمعاتِ مُعيَّنةً. ومن ثَمَّه، فالقيم النسبية قد تتعلَّد حتّن يصبح فيها لكل فئة من المجتمع قيم مُعيَّنة تناسبها، ورُبَّا يشمل ذلك كل فرد فيه، لكنَّ هذه القيم تختلف عن قيم الآخرين كثيراً أو قليلاً، بل إنَّ قيم مجتمع ما أو فرد من أفراده قد تتغيَّ خلال زمن قصير، فلا تظل ثابتة طوال الوقت.

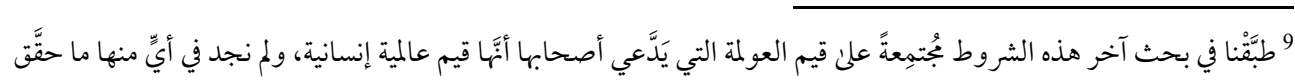

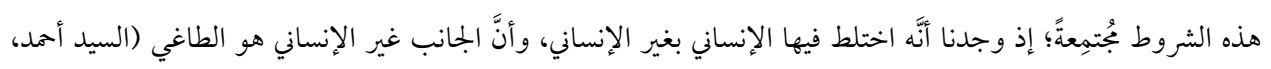

$$
\text { 2015، صـ95-69) }
$$


هذا الر أي بنسبية القيم يقول به كل من يركن أن الإنسان هو مصدر القيم في المجتمع، من علماء الاجتماع، وفلاسفة اللذَّة، وفلاسفة المنفعة، والفلاسفة البرجماتيين، والوضعيين، والو اقعيين عمو ماً،

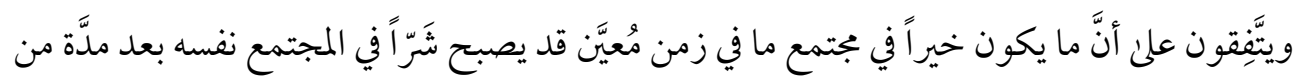
الزمن، وهذا ما يمدث اليوم في المجتمعات الغربية.10

لقد جعل أصحاب هذا الرأي للقيمة وجوداً مستقلاً -نوعاً ما- بحيث يُمكِن الحديث عنها بو صفها موجودات مستقلة، لكنَّهم أتبعوها -في الوقت نفسه- للإنسان، ليس فقط في تغيُّ أحو اله

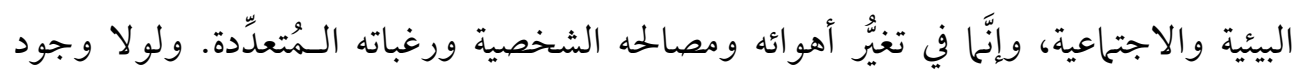
القوانين والتشريعات في المجتمعات التي تأخذ بهذا الرأي لكانت هذه المجتمعات تعاني حالة من الاضطراب والفوضن، ويَصدق فيها قول توماس هويز (ت1679م): "الإنسان ذئب لأخيه

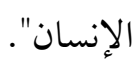

أمّا وصف القيم بالهُطلَقة فيعني عدم التزامها بقيود الزمان، والمكان، والجماعات، والأفراد. وخلافاً لأصحاب الرأي السابق، فإِنَّ القائلين بهذا الرأي لايُرجِعِون مصدر القيم إلنى الإنسان، أو إلنا المجتمع وأحو اله، وإنَّمَ يُرجِعونه إلنى الله سبحانه وتعالمن، أو -باصطلاح أفلاطون- إلنى مثال الخير، أو إلنا

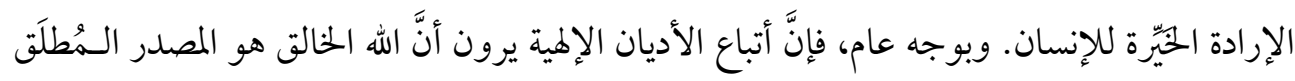
للقيم.

ويرىن أصحاب هذا الاتجاه أنَّ ثبات القيم وإطلاقها من كل القيود يفضي إلن استقرار المجتمعات، والحدِّ من الاختلافات والخلافات والصراعات، ليس فقط بين فئات المجتمع الواحد وأفر اده، وإنَّما بين المجتمعات المختلفة كذلك.

10 علن سبيل المثال، كانت العلاقة السليمة بين الرجل والمرأة في الغرب -حتّن الحرب العالمية الثانية تقريباً- هي العلاقة ضمن

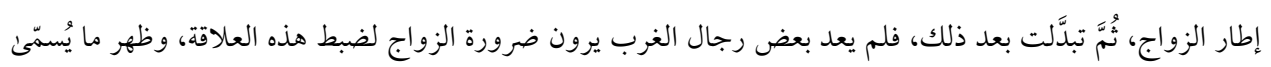

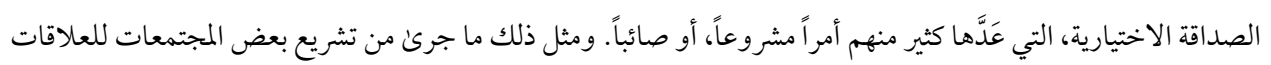
المثلية، وعَدِّها حقِّاً شخصياً بعدما كانت شَرَّاً. 
ويوجد فريق ثالث حاول الجمع بين الرأيين بالقول إنَّ القيم مُطلَّة في جوانب، ونسبية في

جوانب أُخرىن، كأنْ يقال: إنَّ القيم مُطلَقة بو صفها مبادئ نظرية، لكنَّها نسبية في جانبها العملي. ولسنا هنا في مقام تفصيل هذه الآراء عند أصحابها، وإنَّنا نحن بصدد محاولة استجلاء حقيقة

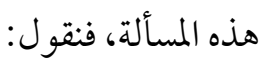

لا ينبغي أنْ يغيب عنّا أنَّ القيم -على اختلافها- لا بُدَّ أنْ تتجسَّد في واقع الحياة الإنسانية،

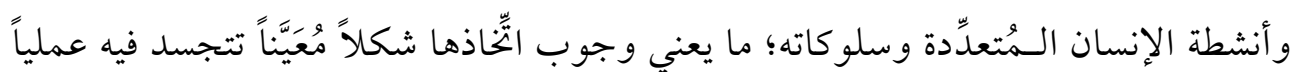
علن أرض الواقع الذي به يتحقَّق معنى القيم. وهذا يعني أنَّ الشكل العملي الذي تتجسَّد فيه القيمة ليس هو القيمة نفسها، وإنَّما هو شكل وتعبير عملي عن القيمة. ومن هنا نرئ أنَّ القيمة من حيث هي فكرة، أو مبدأ، أو صفة -كما تَقدَّمَ في تحديدنا إيّاهايُمكِن أنْ تتشكَّل في أكثر من شكل أو صورة، من دون أنْ يُحِلَّل ذلك بالقيمة، أو يُغيِّرها. ولعلَّ إيراد بعض الأمثلة يزيد هذه الفكرة وضوحاً، ونبدأ بمثال معروف، هو قيمة إكرام الضيف11 (تدخل في مجال قيم التعامل مع الآخر)؛ فتجسيد هذه القيمة في واقع الناس له أشكال عديدة، منها إعداد وليمة من لحم الضأن، أو من لحم الدجاج، أو من لحم الحصان، 12 وقد يقتصر الأمر علن كِسْرة من رغيف خبز، أو شِقّ تمرة. فهذه وغيرها أشكال تتجسد فيها قيمة الكرم، وهي تتغيَّر بتغيُّر الأحوال والظروف والإمكانات.

ومثال آخر هو اللباس، والقيمة فيه -بحسب السياق الإسلامي- ستر العورة للرجال و النساء (تقع في ججال قيم تعامل الإنسان مع ذاته)؛ إذ تتجسَّد هذه القيمة في ارتداء أنواع من 11 أكَّد هذه القيمة رسول الله البخاري ومسلم. 12 في كازاخستان يُكِِمون الضيف العزيز بذبح حصان أو فرس له. 


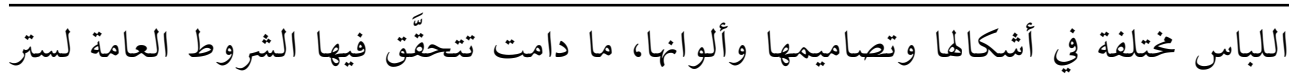
العورة.

و مثال آخر (يقع في مجال التعامل مع الآخر ) يتصل بإدارة الشؤون العامة في المجتمع، بها في ذلك السياسة، وهو قيمة الشورىن. وبتطبيق مفهوم "المخالفة"، فإنَّ الشورى تعني عدم استئثار

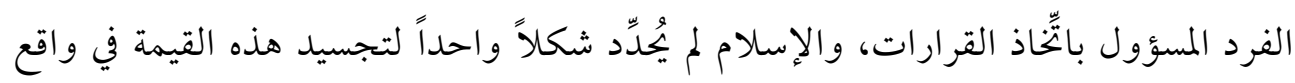
الحياة الإنسانية، وترك ذلك للظروف والأحوال التي تناسب هذا الشكل أو غيره؛ فقد تكون الشورىن بتكوين هيئة استشارية من أهل الرأي أو أهل الحلّ والعقد في المجتمع، أو بإجراء انتخابات وتشكيل برلمان، أو بعمل استفتاء، أو إعداد دراسات علمية، أو غير ذلك ميّا يُحقِّق قيمة الشورن، ويُجسِّدها و اقعاً عملياً.

والشيء نفسه ينطبق على القيم الأُخرىن، مثل: قيمة العدل، وقيمة الإحسان، وقيمة التعاون (علن البرّ والتقوى)، وقيمة برِّ الوالدين، وقيمة التقوى (في بجال التعامل مع الله الخالق)، وغير ذلك من القيم الـمُعتبَرة في السياق الإسلامي؛ إذ تتجسَّد كلّّ منها في عِدَّة أشكال تختلف باختلاف أحو ال الناس والمجتمعات.

و الخلاصة أنَّ القيم في السياق الإسلامي، من حيث هي فكرة، أو مبدأ، أو صفة، إنَّام هي

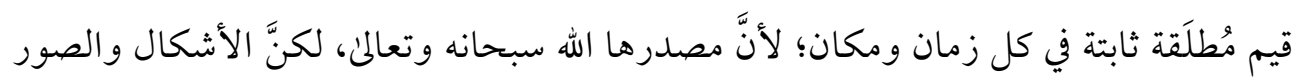
التي تتجسد فيها القيم عديدة ومُتغيِّة بتغيُّر المكان و الزمان والأحو ال، مع بقاء القيم التي تُمثّلّها ثابتة.

لقد تقدَّمت الإشارة إلنا أنَّ ثبات القيم يؤدي إلنا استقرار الحياة الإنسانية الاجتهاعية،

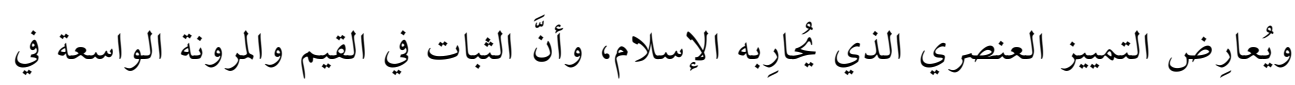
تجسيدها يفي بمطلب التغيُر المكاني والزماني والاجتماعي في أحوال الإنسان. 


\section{سادساً: المرجعية القيمية في التعليم الجامعي \\ 1. المقصود بالتعليم الجامعي:13}

التعليم الجامعي هو مرحلة مُتقدِّمة من مراحل التعليم تقوم به الجامعات. وتأتي هذه المرحلة -

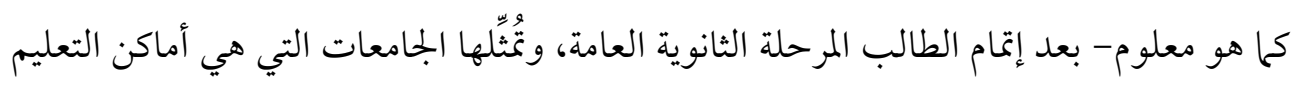
العالي؛ أي التعليم الـمّتخصِّص في مختلف فروع العلم. وفيها يبدأ الطالب اختيار تخصُّص ما من بين تخصُّصات علمية عديدة، وتتركَّز جهوده بدايةً علن اكتساب مزيد من العلم في مجال تخصُّصه، وصولاً إلنا آخر منجزات العلم وتطوُّراته في بجال التخصُّص، وذلك بقدر طاقته والظروف الأُخرىن حوله. أمّا آخر مر احل التعليم الجامعي فهي مرحلة الدراسة لنيل شهادة الدكتوراه.

ولأنَّ العلوم في عصرنا الحاضر تخطو خطوات متسارعة؛ فقد اضطرت الجامعات إلن التوشُع لمواجهة هذا التقدُّم ومتابعته في مختلف حقول العلم، فازداد عدد الكليات الجامعية، وعدد الأقسام العلمية، لا سيَّا بعد منتصف القرن العشرين الميلادي، وما يز ال ذلك مستمراً حتّى يو منا هذا. ويمتاز التعليم الجامعي من التعليم العام بميزة التخصُّص والتخصُّص الضِيّى، الذي له إيجابيات وسليات؛ فمن إيجابياته تيسير الإسهام في تقدُّم العلم في بجال التخصُّص الضيّق جدَّا، ومن سلبياته حصر ذهن المُتخصِّص وعقله في بجال علمي ضيّق جدًا يصعب معه التو اصل العلمي مع التخصُّصات الأُخرى القريبة من المجال العام لتخصُصهـ؛ 15 ما يُعَدُّ اليوم مشكلة بحاجة إلن إعادة نظر وعلاج ما أمكن إلنى ذلك سبيلاً.

13 ما نورده هنا عن التعليم الجامعي هو أساساً نتيجة خبرة شخصية طويلة في التعليم الجامعي.

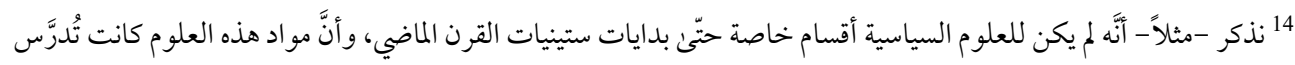

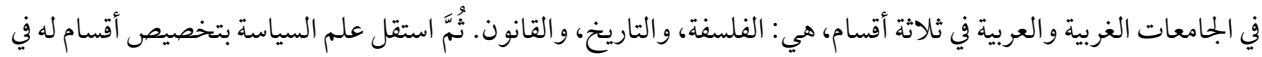

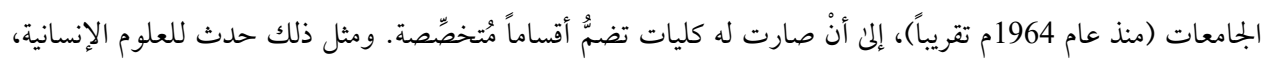

$$
\text { و العلوم الإدارية، وغيرها. }
$$

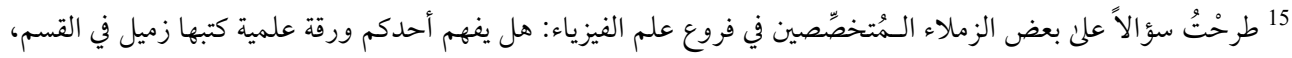

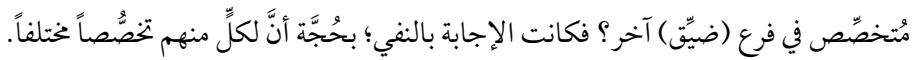




\section{2 أهداف التعليم الجامعي:}

يوجد أكثر من هدف يُتوقَّع من التعليم الجامعي تحقيقه في ما يخصُّ الطلبة والمجتمع، وهذه أبرز الأهداف:

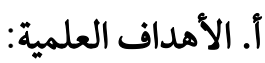

- تأهيل الطلبة في مختلف العلوم، ومواكبة ما يتوصَّل إليه العلم في مجال تخصُّصاتهم في

$$
\text { الجانبين: النظري، والعملي (التطبيقي). }
$$

- ممارسة البحث العلمي، وتشجيعه علن مستوىن الطلبة، ومستوكن أعضاء هيئة التدريس،

$$
\text { ومستوىن الباحثين الـمتّفرِّغين ضمن مؤسسة الجامعة. }
$$

- نشر البحوث العلمية الأصيلة - ما أمكن - في كتب، ودوريات علمية مُتخصِّصة. - مراجعة المناهج الدراسية وتطويرها لمو اكبة الجديد في العلوم و التغيُرات في الحياة، ومراعاة ما بين العلوم من علاقات تكاملية. - اعتماد اللغة العربية لغة أُولن في التعليم الجلامعي بالجامعات العربية أولاً، ثُمَّمَ بالجامعات الإسلامية -ما أمكن -؛ حفاظاً علن الهويَّة الثقافية للتعليم و الطلبة.

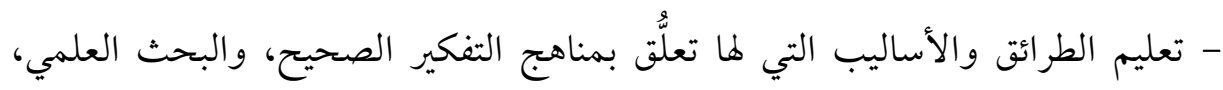
والتفكير النقدي، ومعاييره. - ترسيخ المبادئ والمهارات الخاصة بالحو ار والتفاهم العلمي مع الآخر.

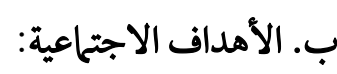

- ترسيخ القيم الاجتماعية الإيجابية (الحيّيّة) لدىن الطلبة، وتخليصهم من القيم الاجتماعية

السلبية (الشَّرّ انية).

- تعزيز مفهوم "المواطَنة" لدىن الطلبة، وترسيخ الهويَّة الثقافية الوطنية العربية الإسلامية في نفوسهم. - الإسهام في تحقيق العدالة الاجتحاعية وتعزيزها بالوسائل المناسبة، بها في ذلك الشورئ، والديمقراطية. 
- إعداد القوئ البشرية اللازمة لسدّ حاجة المجتمع من الوظائف والمهن المختلفة. - إسهام مخرجات التعليم الجامعي في تحقيق التنمية الشاملة والمستدامة في مختلف المجالات. - خدمة المجتمع -ما أمكن - بالتعاون مع مؤسساته المختلفة.

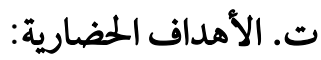

يُقَصد بها إسهام التعليم الجامعي في إنشاء حضارة عزيزة قوية. (للكشف عن مفهوم الحضارة، انظر: السيد أحمد، 2015، ص69-66) . وهذا يتطلَّب تو افر رؤية استراتيجية مُوجَّهة بعقيدة إيجابية، إلنا جانب علم نظري وعملي مُكتسَب، ثَُّّ علم منتج محلياً غير مستورد، وكذلك إنفاق مالي سخي، وقبل ذلك ومعه إرادة جماعية حُرَّة، وقوَّة تحمي هذه الإر ادة وتدعمها. فالتعليم الجامعي يُسهِمِ أولاً في عنصر العلم، ثُمَّ في عنصر توضيح الرؤية الاستراتيجية وترسيخها. أمّا عنصر الإنفاق الملالي فهو مسؤولية مُشترَكة بين الدولة ومؤسسات المجتمع الاقتصادية، ويُسِِمَ التعليم الجامعي (الجامعات) بقدر منه. وفي ما يخصُّ عنصر الإرادة الحوَّة، فإنَّ التعليم العالي يُسهِهم في نشر الوعي بهذه الإرادة وتشكيلها. أمّا القوة الحامية لهذه الإرادة وللنشاط الحضاري فأساسها المجتمع عامة، والدولة بوجه خاص.

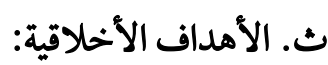

لا تُثمِمر الأهداف الوارد ذكرها آنفاً إلّا إذا تحقَّقت عن طريق سلوكات وتعاملات خَيِّة؛ أين كانت محكومة بقيم إيجابية خَيِّة؛ فقيم الخير هي أثبه بالسياج الذي يحيط بكل سلوك، وكل سلوك

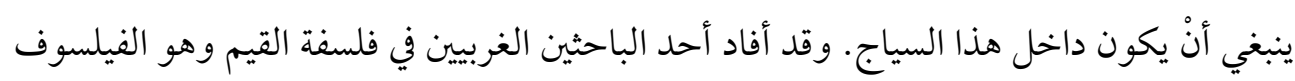

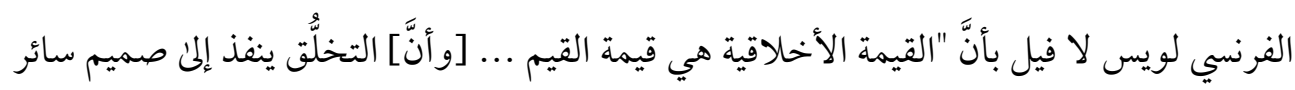

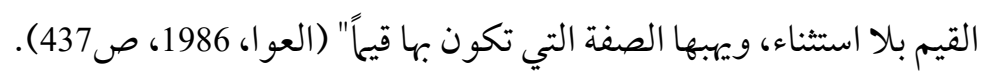

وتأسيساً علن ذلك، يُمكِن إجمال الأهداف الأخلاقية للتعليم الجامعي في ترسيخ القيم الإيجابية (الخِّرة) التي تضبط سلوك العاملين في التعليم الجامعي (الأساتذة، والطلبة) في تعاملهم مع جوانب الوجود. أمّا السبيل إلى تحقيق ذلك فيكون بأساليب مُتعدِّدة (مباشرة، وغير مباشرة)، أهمها القدوة الحسنة. 


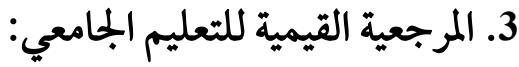

يسعى التعليم الجامعي لتحقيق أهداف علمية، واجتاعية، وحضارية، وأخلاقية؛ ما يُحِّمّ أنْ

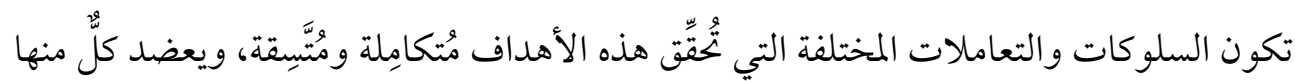

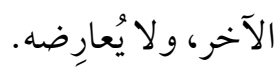

وإذا كان لزاماً ضبط هذه السلوكات والتعاملات بقيم تضبط كل سلوك وتعامل منها،

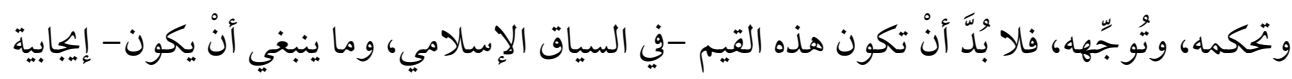

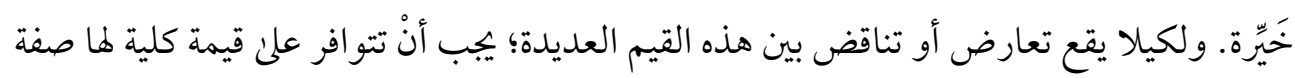
الخيرية، وتكون بلفظ آخر قيمة القيم كلها.

وهذه الأهداف لائَُّ أنْ تنطلق من رؤية كلية للوجود، كما قال بذلك كثير من الفلاسفة والمُشتِغِلين

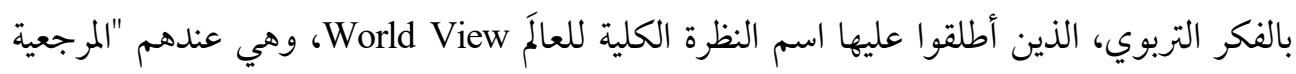
النهائية" (ملكاوي، 2020، ص535). وبحسب تعريف عبد الوهاب المسيري، فـ: "هي الفكرة الجوهرية

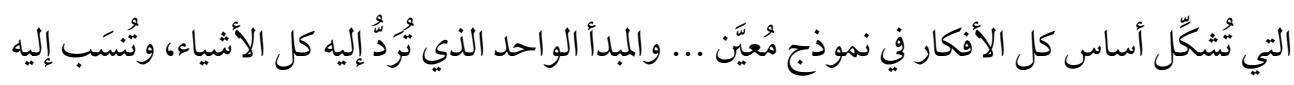

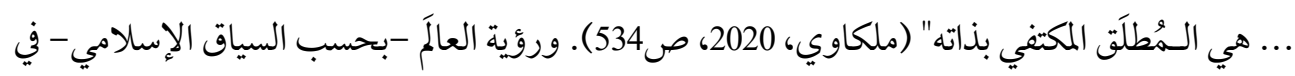

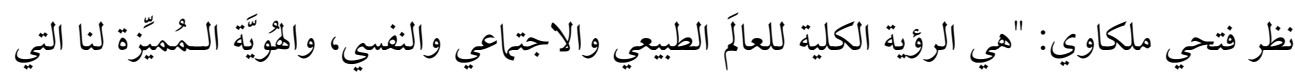

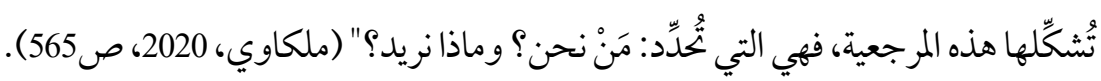

ومن التعريفات الغربية لمفهوم "النظرة الكلية للعالَّ"، تعريف ديفيد ناييل David Naugle:

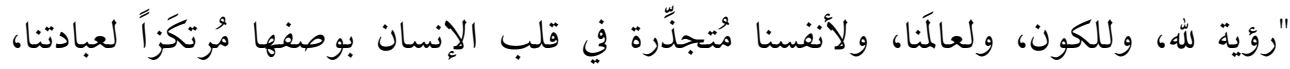

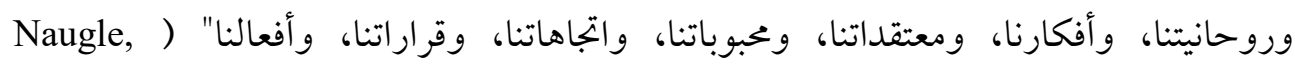
.(www.dbu/naugle/pdf/worldview وبالنظر في التعريفات الواردة آنفاً، والتعريفات الأُخرىن لهذا المصطلح، يُلاحَظ أنَّها -في

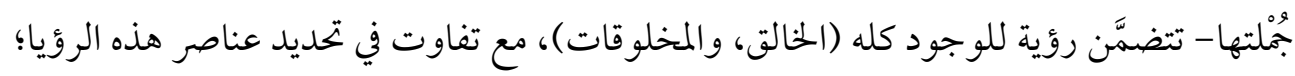


إذ بعضها لا يُدخِل الله ضمن رؤيته. ولهذا، وانسجاماً مع سياق هذا البحث ومصطلح الماته (السمتتقدِّم

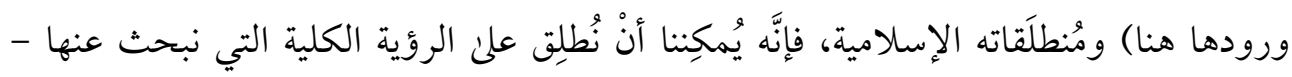
بو صفها مرجعية فكرية نظرية- اسم الرؤية الكلية للوجود (خالقاً، ومخلوقاتٍ) Existence View. والآن سنبحث عن قيمة القيم التي ستكون مرجعاً لجميع السلوكات العملية في التعليم الجامعي، وعن المرجعية الكلية النظرية (الفكرية) لجميع السلوكات النظرية في التعليم الجامعي، بحسب الـمُنطلَقات الإسلامية.

\section{أ. قيمة القيم (القيمة المرجعية الكلية):}

قبل البحث عن المرجعية الخيّرة للقيم في التعليم الجامعي، سنبحث أولاً عن المرجعية الخيّرة

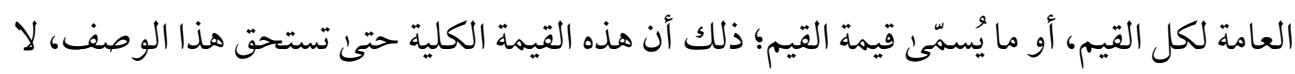
بدَّ أن تكون ظاهرة وسارية في كل القيم الجزئية في عائلات قيم كل قسم من أقسام الوجود. و وإذا كان

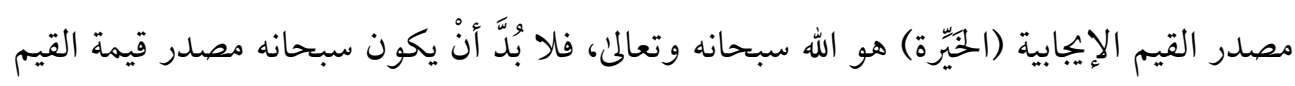
(هي أيضاً قيمة). وإذا كان الهدف الأسمى للإنسان في حياته هو تحقيق خيره وكماله، وكان تحديد ذلك الخير لا يكون إلا من الله سبحانه من خلال طاعته والالتزام بأمره ونهيه، وكان هذا الالتزام و الطاعة هو معنى عبادة الله ومفهومها، وإذا كانت العبادة هي الغاية من خلق الله الإنسان. وهو

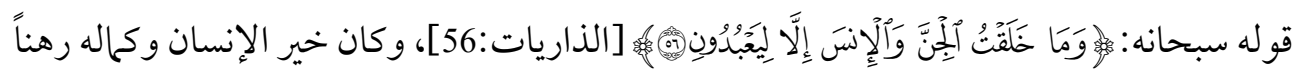

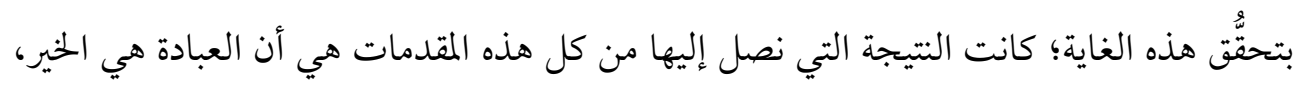

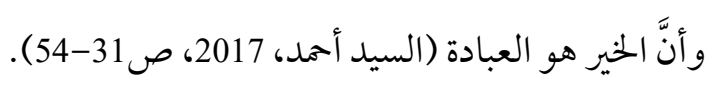

ولا يكون كل سلوك أو تعامل للإنسان (جليلاً كان، أو بسيطاً) خيراً إلّا إذا كان عبادة لله سبحانه وتعالنا، عندئذٍ تصبح العبادة هي القيمة الكبرىن، أو قيمة القيم. وإذا كانت القيم تحكم على لئ

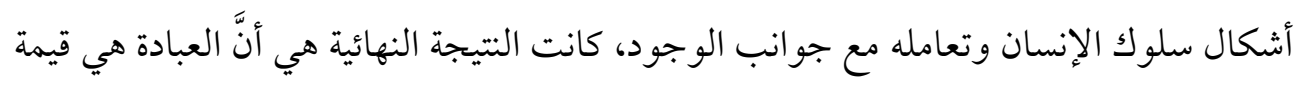
القيم لكل جوانب سلوك الإنسان وتعاملاته العملية في الحياة بلا استثناء؛ أو بلفظ آخر القيمة المرجعية الكلية. وإذا كان السلوك والتعاملات في التعليم الجامعي جانباً من سلوك الإنسان 


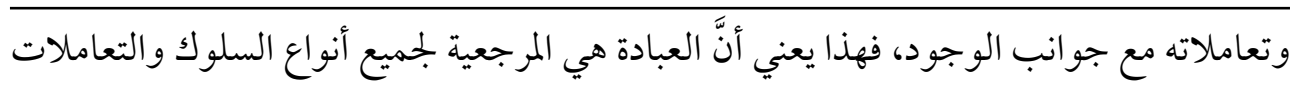
العملية في التعليم الجامعي (كل ما يقوم به الأساتذة، والطلبة، وغيرهم من العاملين في التعليم (الجامعي) (1) (n)

وبتوضيح عام نقول: إذا وُجِد في التعليم الجامعي سلوك أو تعامل لا تتجسَّد فيه هذه القيمة الكلية (أيْ طاعة الله، وفعل ما أمر به)، فإِنَّه لن يكون خيراً حقيقياً، وإنْ بدا لبعض الناس أنَّه خير.

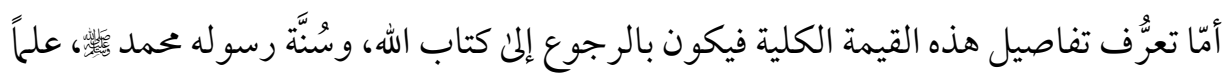
بأنَّ العلوم الشرعية بحثت -وما تز ال تبحث - في هذه التفاصيل بطر ائق من التناول مختلفة.

\section{ب. المرجعية الكلية النظرية (الفكرية) للتعليم الجامعي:}

المرجعية هي ما يُرجع إليه، أو المرجوع إليه في المنازعات بين الناس (ملكاوي، 2020، ص533).

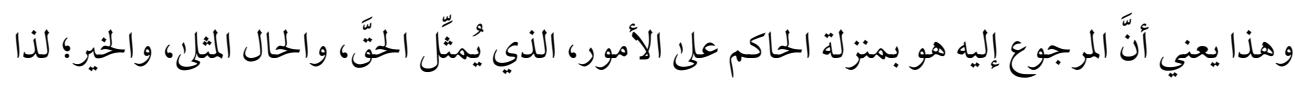

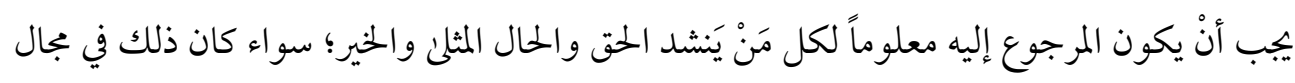
التعليم الجامعي، أو في غيره من مجالات الحياة، ومن هنا تأتي أهمية المرجعية (أو المرجوع إليه). وللمرجعية مستويات عديدة، منها المرجعية الكلية أو النهائية (ملكاوي، 2020، ص533)، وهي المرجوع إليها في كل تعاملات الإنسان مع الوجود عامة، ويُطلِق عليها كثير من الباحثين اسم النظرة الكلية للعالمَ World View، وقد تقدَّم القول بأنَّا نرى تسميتها النظرة الكلية للوجود الِّد Existence View و أنَّها تتضمن المعرفة الكلية (غير المُففصَّلة) بحقيقة الوجود (خالقاً، ومخلوقاتِ)، وعناصرها الرئيسة هي: الله، والإنسان، والكون الطبيعي (عالَّ الشهادة)، وعالَّ الغيب، والحياة الإنسانية. أمّا المرجعية الكلية النظرية (الفكرية) للتعليم الجامعي فهي -بالضرورة- جزء من النظرة الكلية للوجود (تتعلَّق بجانب من الوجود، هو التعليم الجامعي)، لكنَّها لا تتعارض مع أيِّ من عناصرها، حتّى إنَّهُ يُمكِن اعتبار هذه المرجعية في التعليم العالي المرجعيةً الكلية للوجود. 


\section{مصدر المرجعية الكلية للوجود}

في معرض البحث عن المرجعية الكلية للوجود، لن نشير إلن آراء الباحثين الغربيين والمسلمين -

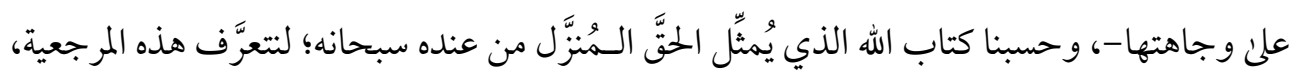
وسنبدأ باياير اد الآيات الكريمة التي تُشِدنا إليها، وتُبيِّها.

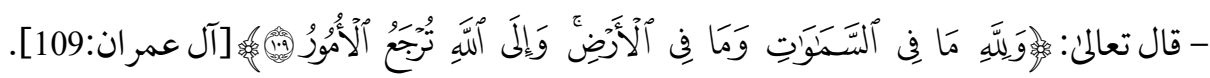
- قال تعالمن:

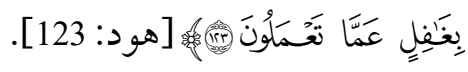

لقد أشارت الآية الأُولنا إلنا الكون الطبيعي (السماوات، والأرض)، أو إلنى العالم الطبيعي، وهو عالَم الشهادة، في حين أشارت الآية الثانية إلى عالمَ الغيب. وبذلك جمعت هاتان الآيتان عالمَي الشهادة والغيب، وأكَّدتا أنَّ الله تعالنا هو المرجعية الكلية والنهائية لكل الأمور والأحداث التي تجري في هذين العالمين معاً (إذ هو سبحانه وتعالما خالق عالمي الغيب و الشهادة).

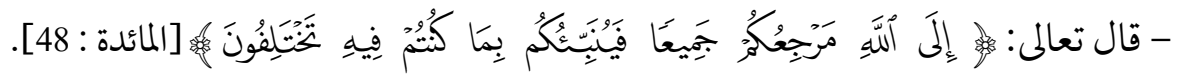

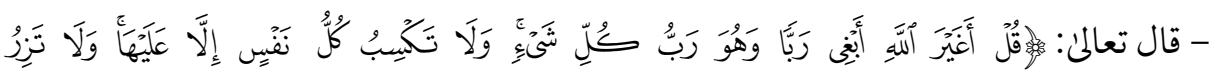

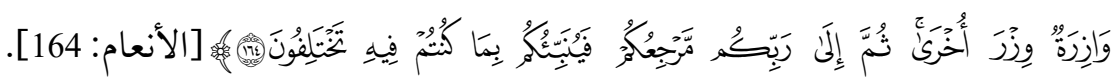
أكَّدَت هاتان الآيتان أنَّ الله ربنا61 سبحانه وتعالنا هو المرجوع إليه في الآخرة؛ ليُعِلمنا ما كنّا فيه ختلفين في هذه الحياة بخصوص آرائنا ومعتقداتنا وسلو كنا.

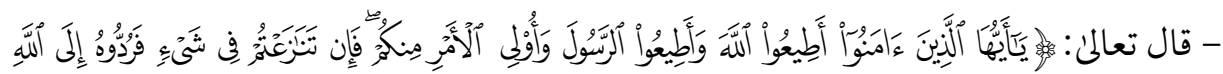

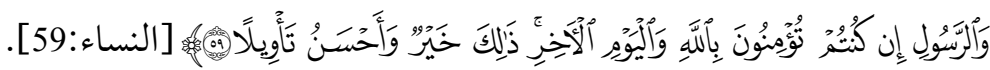

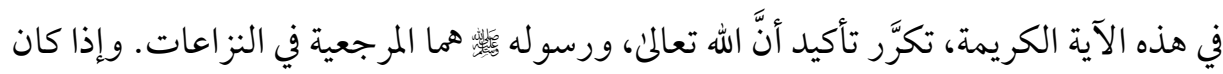
الرسول لا ينطق عن الهوئ، وما يأتي به هو وحي يوحن به إليه من عند الله، وهو السمّبلّغ عن الله 16 نُذَّرّ هنا أنَّ الله هو الربُّ؛ فالهُ خالق كل شيء، والربُّ لكل شيء ذات واحدة (الله ربُّ العالمين). انظر توضيحاً للفرق بين

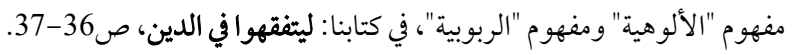


السمُبيِّن لمراده في ما أتى به، فإنَّ الله تعالنا هو المرجعية الكلية النهائية التي يُرجَع إليها في منازعات

$$
\text { البشر واختلافاتهم. }
$$

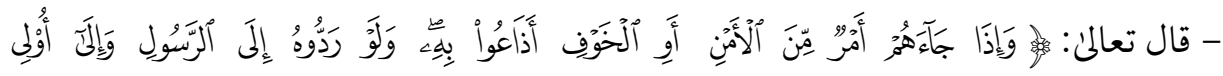

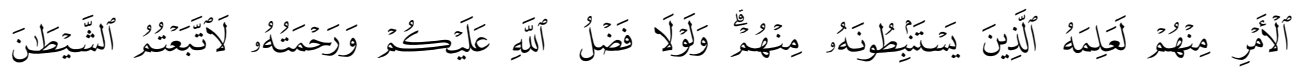

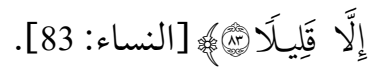

في هذه الآية الكريمة، تكرَّر تأكيد مرجعية الله تعالن والرسول لَّل، مع زيادة أُولي الأمر ـ وأُولو الأمر -في ما نرك- هم الذين يأمرون الآخرين ويُرجَع إليهم من حُكّام، أو علماء، أو مسؤولين، أو مُربيّن، لكن هذه الفئات ليست كلها ضمن المرجعية التي ثُرَدُّ إليها الخلافات والمنازعات، وإنَّا بعضهم وهم القادرون منهم علن استنباط الأحكام -الكامنة- في المرجع (القرآن الكريم) الذي تري

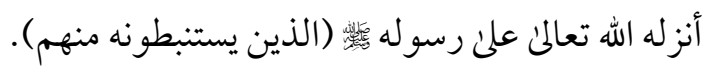
ومن ثَمَّ، فكل هذه الآيات تُؤِّد أنَّ الله تعالنا هو المرجعية الكلية للوجود. ولكنْ، كيف يكون

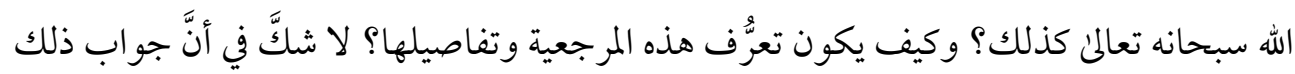

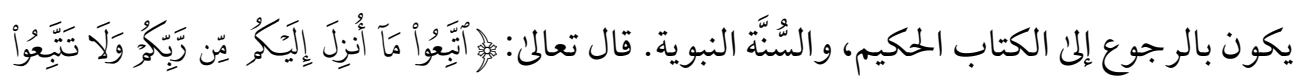

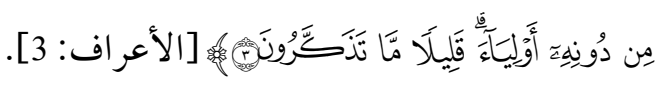
لقد بيَّن الوحي الإلهي الخاتم الحقائق الكلية لعناصر الوجود الكبرىن (الله، والإنسان، وعالمًا

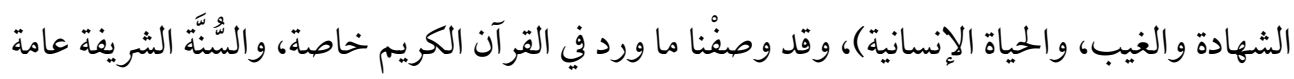

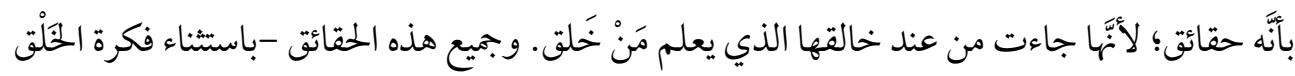
العامة التي يُمكِن إثباتها عقلاًَ- هي غيب لا يملك الإنسان الوسائل والقدرة علن إدراكها. والخلاصة أنَّه إذا وُجِد في التعليم الجامعي أفكار تتعارض مع هذه الحقائق الكلية لأيِّ من عناصر الوجود، فإنَّ المرجعية الكلية النظرية تتدَّّل لترفض هذه الأفكار، وتُطالِب بالبحث الجادِّ للوصول إلمن ما يتَّفِق مع هذه المرجعية؛ إذهي حقِّ من عند الحقّ سبحانه. 
عرضنا -في ما تقدَّم- مفهوم "القيم"، وتصنيفها، والقيم الإيجابية (الحِِّّة) في ضوء اجتهادنا

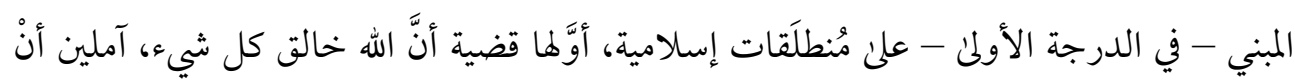

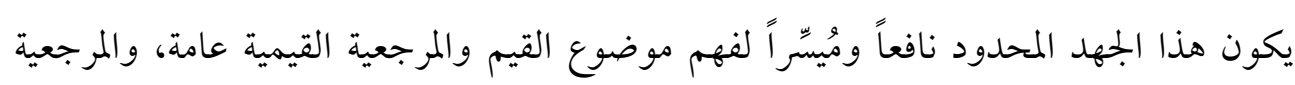

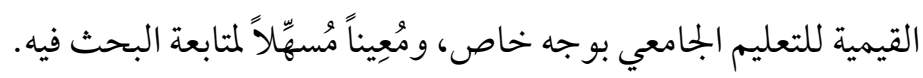

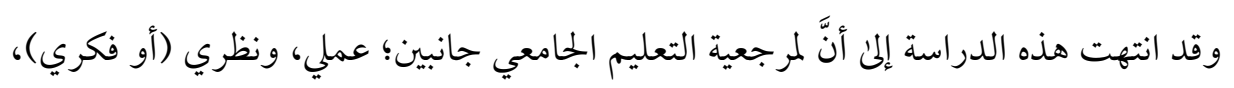

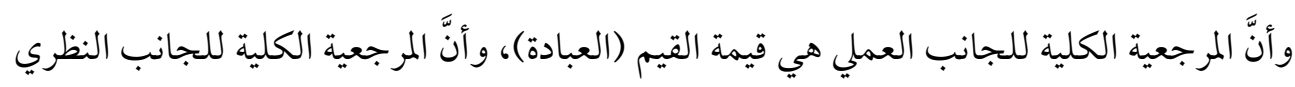

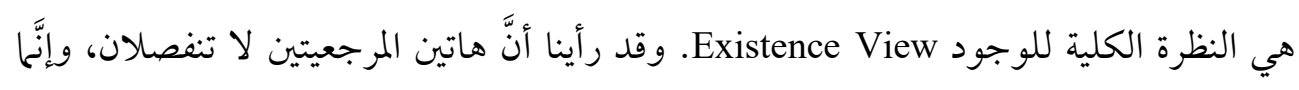

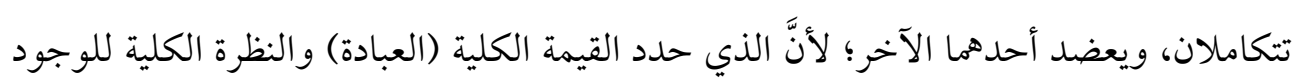

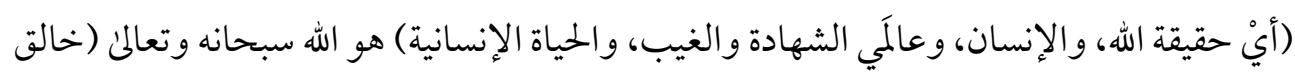
كل شيء).

والحقيقة أنَّ موضوع القيمة الكلية، وموضوع النظرة الكلية للوجود، بحاجة إلنا بحث خاص

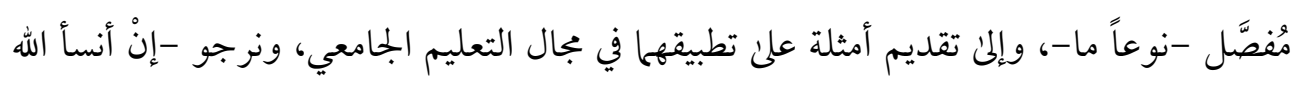

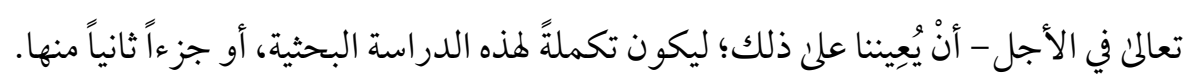


السيد أحم، عزمي طه (2008). علم الثقافة الإسلامية: مدخل، عمّان: المؤسسة العربية الدولية للنشر والتوزيع.

السيد أحمد، عزمي طه (2015). الوجه الآخر للفلسفة: مدخل معاصر، إربد: عالم الكتب الحديث. السيد أحم، عزمي طه (2015). مدخل إلى الثقافة الإسلامية، عَّان: (د.ن). السيد أحمد، عزمي طه (2015). هموم ثقافية في عصر العولمة: دراسات فلسفية تأصيلية، إربد: عالم الكتب الحديث.

$$
\text { العوا، العيد أحمد، عزمي طه (2017) . ليتفقهوافي الدين، عِّان: وزارة الثقافة. }
$$

مجمع اللغة العربية في القاهرة (2011). المعجم الوسيط، ط5، القاهرة: مكتبة الشروق الدولية.

ملكاوي، فتحي حسن (2020). الفكر التربوي الإسلامي المعاصر: مفاهيمه ومصادره وخصائصه وسبل إصلاحه، فرجينيا-عَّان: المعهد العالمي للفكر الإسلامي.

\section{References:}

Al-'Awwa, A. (1960). Al-Qìmah al-Akhlāqiyyah. Damascus: Maṭba 'at Jāmi at Dimashq.

Al-'Awwa, A. (1986). Al- 'Umda fi al-Qiyam. Damascus: Dār Ṭallās.

Al-Sayyid Ahmad, A. (2008). 'Ilm al-Thaqāfah al-Islāmiyyah: Madkhal. Amman: alMu'assasah al-'Arabiyyah al-Dawliyyah li al-Nashr wa al-Tawzī'.

Al-Sayyid Ahmad, A. (2015). Al-Wajh al-'Ākhar li al-Falsafah: Madkhal Mu 'āṣir. Irbid: 'Âlam al-Kutub al-Hadīth.

Al-Sayyid Aḥmad, A. (2015). Humūm Thaqāfiyyah fì 'Aṣr al-'Awlamah: Dirāsāt Falsafiyyah Ta'șiliyyah. Irbid: 'Ālam al-Kutub al-Hadīth.

Al-Sayyid Ahmad, A. (2015). Madkhal ila al-Thaqāfah al-Islāmiyyah. Amman: (D. N.).

Al-Sayyid Ahmad, A. (2017). Li Yatafaqqahū fì al-Dīn. Amman: Wizārat al-Thaqāfah.

Majma 'al-Lughah al- 'Arabiyyah fĩ al-Qāhirah. (2011). Al-Mu 'jam al-Wasīt (5 ${ }^{\text {th }}$ ed.). Cairo: Maktabat al-Shurūq al-Dawliyyah.

Malkawi, F. (2020). Al-Fikr al-Tarbawī al-Mu'āṣir: Mafāhīmuh wa Maṣādiruh wa Khașāișuh wa Subul Iṣlāhih. Virginia, Amman: International Institute of Islamic Thought.

Naugle, David. World View: Definitions, History, and Importance of a concept, (www3.dbu/naugle/pdf/worldview) 


\title{
Values and Value Reference in University Education
}

\section{Azmi Taha El-Sayed Ahmad}

\begin{abstract}
This study aims to elucidate the concept of "value" as adopted by the author, and to highlight the importance of values in life. It seeks to address the issue of value classification in general, presenting a specific classification of values developed by the author, with categories that follow ontological divisions. Besides demonstrating that the source of positive (good) values is God Almighty, it deals with the question of the relativity and absoluteness of values, confirming the invariability of values, and the multiplicity of the forms of their actualization in reality. Moreover, the study discusses university education and its scientific, social, civilizational, and moral goals, as well as its frame of reference. It concludes that the frame of reference for university education has two aspects: practical and theoretical (intellectual), and that the overall reference for the practical is the value of values (worship), while the one for the theoretical is the holistic view of existence. The study also concludes that the two aspects of reference are complementary, indicating that their source is one, God Almighty, Creator of everything.
\end{abstract}

Keywords: Values, positive values, the value of values, holistic vision of existence, value frame of reference 